\title{
Ion dynamics in solid electrolytes for lithium batteries
}

\section{Probing jump rates and activation energies through time-domain Li NMR}

\author{
Marlena Uitz ${ }^{1}$ - Viktor Epp ${ }^{1}$ Patrick Bottke ${ }^{1}$ - Martin Wilkening ${ }^{1,2}$ (D)
}

Received: 6 September 2016 / Accepted: 6 February 2017 / Published online: 7 March 2017

(C) The Author(s) 2017. This article is published with open access at Springerlink.com

\begin{abstract}
All-solid-state batteries with ceramic electrolytes and lithium metal anodes represent an attractive alternative to conventional ion battery systems. Conventional batteries still rely on flammable liquids as electronic insulators. Despite the great efforts reported over the last years, the optimum solid electrolyte has, however, not been found yet. One of the most important properties which decides whether a ceramic is useful to work as electrolyte is ionic transport. The various time-domain nuclear magnetic resonance (NMR) techniques might help characterize and select the most suitable candidates. Together with conductivity measurements it is possible to analyze ion dynamics on different length-scales, i.e., to differentiate between local, within-site hopping processes from long-range ion transport. The latter needs to be sufficiently fast in the ceramic, in the best case competing with that of liquid electrolytes. In addition to conductivity spectroscopy, NMR can help understand the relationship between local structure and dynamic parameters. Besides information on activation energies and jump rates the data also contain suggestions about the relevant elementary steps of ion hopping and, thus,
\end{abstract}

Support by the Deutsche Forschungsgemeinschaft (DFG) is highly appreciated (FOR 1277).

Martin Wilkening

wilkening@tugraz.at

1 Christian Doppler Laboratory for Lithium Batteries, and Institute for Chemistry and Technology of Materials, Graz University of Technology (NAWI Graz), Stremayrgasse 9, 8010 Graz, Austria

2 Alistore-ERI European Research Institute, 33 rue Saint Leu, 80039 Amiens, France diffusion pathways through the crystal lattice. Recent progress in characterizing ion dynamics in ceramic electrolytes by NMR relaxometry will be briefly reviewed. Focus is put on presently discussed solid electrolytes such as garnets, phosphates and sulfides, which have so far been studied in our lab.

Keywords Solid electrolytes - Nuclear magnetic resonance spectroscopy $\cdot$ Relaxation $\cdot$ Bulk Li ion diffusivity

\section{Introduction}

The march of global warming caused by overmuch greenhouse gas emissions is hoped to be met, at least in the medium run, by powerful electrochemical energy storage systems [1,2]. Abandoning combustion engines will greatly cut our dependencies on fossil fuels. Systems based on mobile lithium ions are currently the most advanced batteries with which most of the portable devices and electric vehicles are powered [2-15]. Although we have witnessed remarkable advances in the last decades further progress in lithium-ion battery technology based on liquid electrolytes [12, 16-18] might crest in the future. All-solid-state lithium metal batteries with solid electrolytes [19-22] (cf. Fig. 1) represent one of the next-generation technologies [23-31].

Such systems, taking advantage of ceramic solid electrolytes [19, 22, 58, 59], are advantageous because of two considerations: (i) turning away from highly flammable liquid electrolytes is expected to greatly improve safety and longevity, i.e., to reduce aging processes; (ii) (highly) dense and electrochemically stable inorganic electrolytes would allow the use of metallic $\mathrm{Li}$ as anode material, instantly increasing current charge capacities. The search for suitable materials that are characterized by ultra-fast ion dynamics 
(a)

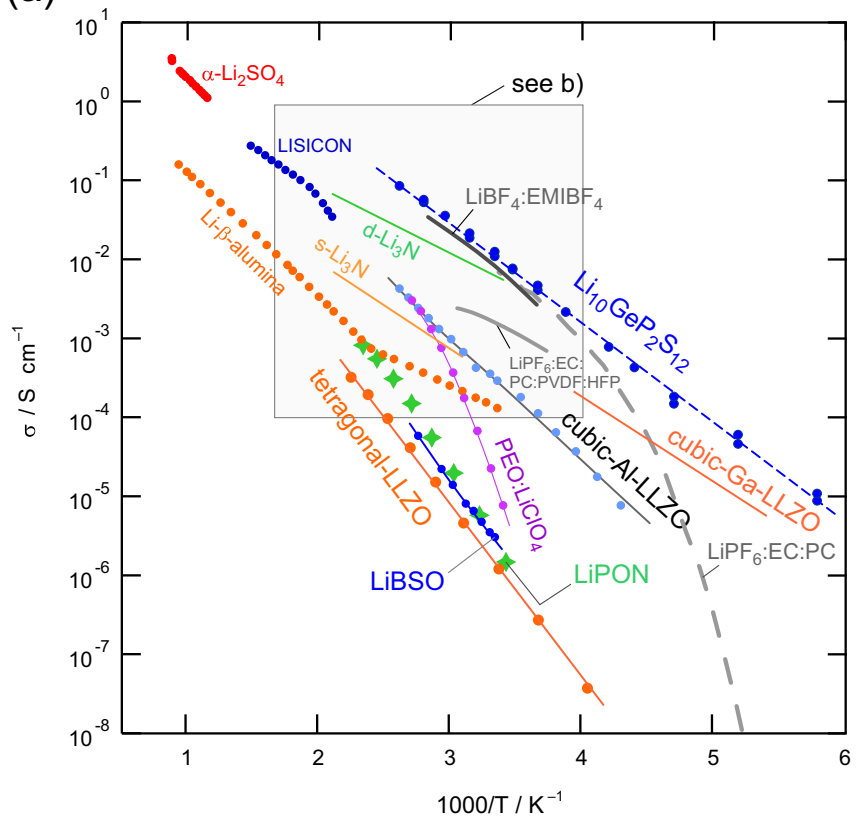

Fig. 1 Temperature dependence of the conductivity of various solid, inorganic electrolytes. For comparison, some liquid electrolytes are also included. For the sake of clarity, in Fig. 1(b) a cut-out is shown including the most important solid electrolytes with high $\mathrm{Li}^{+}$conductivity near ambient temperature. (a) Data were taken from the literature: $\alpha-\mathrm{Li}_{2} \mathrm{SO}_{4}$ [32]; LISICON $\left(\mathrm{Li}_{14} \mathrm{Zn}\left(\mathrm{GeO}_{4}\right)_{4}\right)$ [33]; $\mathrm{Li}-\beta$-alumina [34]; $\mathrm{Li}_{10} \mathrm{GeP}_{2} \mathrm{~S}_{12}$ [35]; s-Li $\mathrm{Li}_{3} \mathrm{~N}$ (pure, sintered) [36]; $\mathrm{d}-\mathrm{Li}_{3} \mathrm{~N}$ (doped with $\mathrm{H}$ ) [37]; tetragonal LLZ $\left(\mathrm{Li}_{7} \mathrm{La}_{3} \mathrm{Zr}_{2} \mathrm{O}_{12}\right)$ [38]; cubic-Al-LLZO $\left(\mathrm{Li}_{7} \mathrm{La}_{3} \mathrm{Zr}_{2} \mathrm{O}_{12}\right.$ with 0.9 wt $\%$ $\mathrm{Al}$ added) [39]; cubic-Ga-LLZO (Ga-containing garnet, bulk values)

and negligible electronic transport has already reached an unprecedented level. If chemically and electrochemically stable against $\mathrm{Li}$ metal, such ceramics can not only be used for lithium metal (or lithium-ion) batteries but also for systems with even higher discharge capacities such as allsolid-state Li/sulfur batteries. Moreover, their implementation in non-aqueous, and possibly even aqueous, Li/oxygen batteries seems to pe promising.

Regarding (hybrid) automotive applications the all-solidstate concept may be advantageous because ceramics easily withstand higher operation temperatures. This feature also enables them to be used in stationary energy storage systems. In the majority of cases ion transport in solid electrolytes is usually some orders of magnitude slower than that in liquid or gel-type organic electrolytes. Over the last couple of years some breakthroughs have, however, been reported. As an example, in 2011 Kanno and co-workers reported on extremely high ionic conductivity $\sigma_{\text {ion }}$ of $1.7 \times 10^{-2} \mathrm{~S} \mathrm{~cm}^{-1}$ for $\mathrm{Li}_{10} \mathrm{GeP}_{2} \mathrm{~S}_{12}$ [35] which exhibits quasi-isotropic three-dimensional lithium diffusion pathways [60]; for $\mathrm{Li}_{7} \mathrm{P}_{3} \mathrm{~S}_{11}$, on the other hand, Seino et al. [52] showed that in heat-treated and highly dense $\mathrm{Li}_{7} \mathrm{P}_{3} \mathrm{~S}_{11}$ $\sigma_{\text {ion }}$ can reach values up to $1.7 \times 10^{-2} \mathrm{~S} \mathrm{~cm}^{-1}$ at room (b)

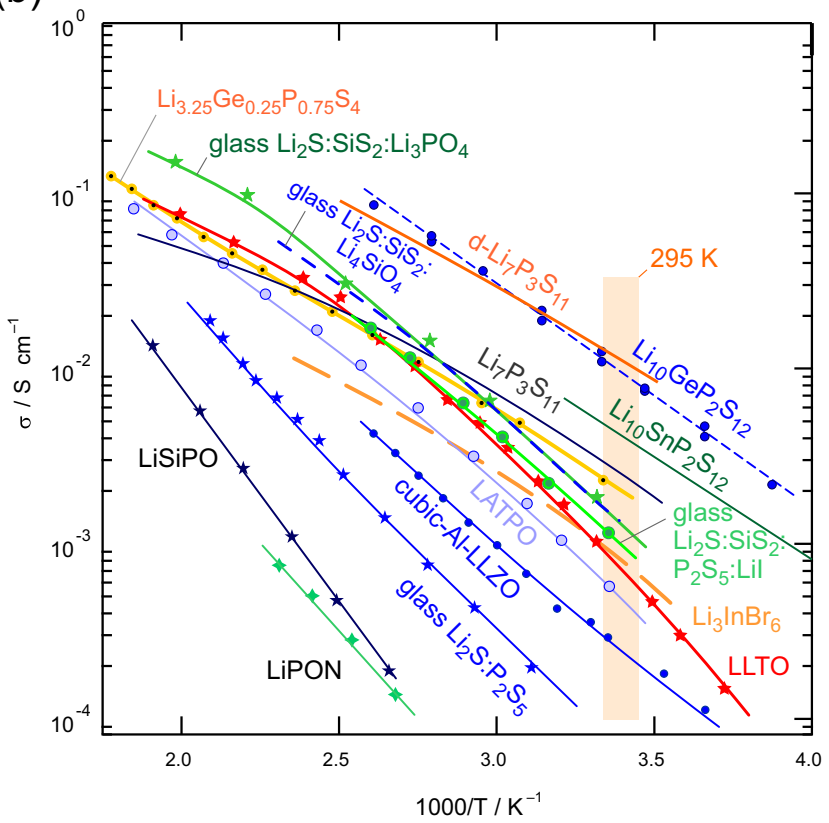

[40]; LiBSO (0.3 $\mathrm{LiBO}_{2}-0.7 \mathrm{Li}_{2} \mathrm{SO}_{4}$, thin film) [41]; LiPON (lithium phosphorous oxynitride, thin film) [42]; $\mathrm{PEO}: \mathrm{LiClO}_{4}$ [43]; $\mathrm{LiBF}_{4}: \mathrm{EMIBF}_{4}$ [44]; $\mathrm{LiPF}_{6}: \mathrm{EC}: \mathrm{PC}$ [45]; LiPF 6 :EC:PC:PVDF:HFP [46]. (b) $\mathrm{Li}_{3.25} \mathrm{Ge}_{0.25} \mathrm{P}_{0.75} \mathrm{~S}_{4}$ [47]; glass $\mathrm{Li}_{2} \mathrm{~S}: \mathrm{SiS}_{2}: \mathrm{Li}_{3} \mathrm{PO}_{4}$ [48]; glass $\mathrm{Li}_{2} \mathrm{~S}: \mathrm{SiS}_{2}: \mathrm{Li}_{4} \mathrm{SiO}_{4}$ [49]; glass $\mathrm{Li}_{2} \mathrm{~S}: \mathrm{SiS}_{2}: \mathrm{P}_{2} \mathrm{~S}_{5}: \mathrm{LiI}$ [50]; glass $\mathrm{Li}_{2} \mathrm{~S}: \mathrm{P}_{2} \mathrm{~S}_{5}$ [51]; $\mathrm{Li}_{7} \mathrm{P}_{3} \mathrm{~S}_{11}$ [51]; $d-\mathrm{Li}_{7} \mathrm{P}_{3} \mathrm{~S}_{11}$ (dense samples) [52]; $\mathrm{Li}_{10} \mathrm{SnP}_{2} \mathrm{~S}_{12}$ [53]; LiSiPO ( $\mathrm{Li}_{4} \mathrm{SiO}_{4}: \mathrm{Li}_{3} \mathrm{PO}_{4}$ solid solution) [54]; LATPO $\left(\mathrm{Li}_{1.3} \mathrm{Al}_{0.3} \mathrm{Ti}_{1.7}\left(\mathrm{PO}_{4}\right)_{3}\right.$ crystal) [55]; $\mathrm{Li}_{3} \operatorname{InBr}_{6}$ [56]; LLTO $\left(\mathrm{La}_{0.51} \mathrm{Li}_{0.34} \mathrm{TiO}_{2.94}\right.$, bulk conductivity) [57]

temperature, too. The same holds for $\mathrm{Li}_{7} \mathrm{P}_{3} \mathrm{~S}_{11}$ that was prepared through spark plasma sintering [61]. Already in 2008 Deiseroth and co-workers reported on argyrodite-type Li ion conductors, especially $\mathrm{Li}_{6} \mathrm{PS}_{5} \mathrm{Br}$, with ionic conductivities being on a par with those of liquid organic electrolytes [62]. Regarding possible oxides, in 2007 Weppner and Thangadurai introduced the garnet $\mathrm{Li}_{7} \mathrm{La}_{3} \mathrm{Zr}_{2} \mathrm{O}_{12}$ (LLZO) with cubic symmetry that is characterized by ionic conductivities in the order of $10^{-4}$ to $10^{-3} \mathrm{~S} \mathrm{~cm}^{-1}$ [63]. In the meantime many LLZO-based materials have been presented and an overview is given in refs. [19, 22] where the relationships between chemical composition, structure and ionic conductivity of the Li-stuffed garnet-type oxide as well as relevant $\mathrm{Li}$ ion conduction mechanisms are discussed. Among the known $\mathrm{Li}$-stuffed garnets, $\mathrm{Li}_{6.4} \mathrm{La}_{3} \mathrm{Zr}_{1.4} \mathrm{Ta}_{0.6} \mathrm{O}_{12}$ and $\mathrm{Al}(\mathrm{Ga})$-stabilized cubic- $\mathrm{Li}_{7} \mathrm{La}_{3} \mathrm{Zr}_{2} \mathrm{O}_{12}$ exhibit the highest Li-ion conductivity $\left(10^{-3} \mathrm{~S} \mathrm{~cm}^{-1}\right.$ at $\left.295 \mathrm{~K}\right)[19,22,40]$. While activation energies derived from impedance spectroscopy lie around $0.2 \mathrm{eV}$ for the sulfides [64], for the highly conducting garnet-based oxides values of ca. $0.35 \mathrm{eV}$ were reported [19]. During recent years titanium phosphates again entered the spotlight; for some of the $\mathrm{Li}_{1.5} \mathrm{Al}_{x} \mathrm{Ti}_{2-x}\left(\mathrm{PO}_{4}\right)_{3}$ samples investigated so far bulk ion 
conductivities have been reported to be in the order of $10^{-3} \mathrm{~S} \mathrm{~cm}^{-1}$ with activation energies ranging from approximately 0.2 to $0.35 \mathrm{eV}$ [65]. An overview of conductivities of earlier and just recently studied ceramic electrolytes is given in Fig. 1.

To study ion dynamics in promising ceramics on the angstrom length scale, that is, from an atomic scale point of view, nuclear magnetic resonance (NMR) can be applied $[18,66,67]$. NMR plays on the various interactions of the $\mathrm{Li}$ spins with external and internal magnetic fields. By sensing the dipolar-magnetic or quadrupolar-electric fluctuations as a function of temperature, through NMR relaxation techniques bulk ion dynamics are probed that shed light on the elementary steps governing ion hopping. Moreover, in ideal cases NMR also allows to draw conclusions about the underlying motional correlation functions [68-72]. In contrast to impedance or conductivity measurements no post-preparation of the synthesized powder, i.e., pressing of dense pellets, applying of electrodes, is necessary. NMR is a non-destructive and non-contact method applicable to all kinds of powder samples or single crystals including also mixed-conducting materials $[73,74]$. Before we present some of the recently collected results on selected electrolytes, the demands on solid electrolytes and all-solid-state batteries are briefly discussed. A high ionic conductivity or diffusivity is just one of several requirements that need to be fulfilled to realize an efficiently working system.

\section{The demands on solid electrolytes and all-solid-state batteries}

A number of hurdles still need to be overcome to develop a long-lasting and powerful all-solid-state system; some of these aspects are illustrated in Fig. 2. Even if an electrolyte with sufficiently high ionic but negligible electronic conductivity is at hand, its chemical and electrochemical stability has to be studied thoroughly. In many cases, especially if nanostructured materials with large interfacial regions are considered [75-77], we do not know much about any possible low electronic contributions. These may lead to slow self-discharge of the whole system during longterm operation. Such long-term observations are also key to other issues. While for thin-film batteries, prepared by cost-intensive sputtering or other (vacuum) deposition techniques, Li metal anodes might be difficult to implement, for bulk-type batteries the use of metal anodes will provide the necessary jump in energy density to make them a serious option for electric vehicles. Although the ceramic acts as a 'dense' membrane the risk of unsolicited Li plating and dendrite formation along grain boundaries is still given [78].

Besides Li dendrites, which may cause short-circuits leading to increased fire hazards, a passivating layer at the electrode-electrolyte interface, see, e.g., ref. [79], as well as at the solid electrolyte-liquid electrolyte interface in hybrid batteries may form [80]. The formation of such layers, which in most cases consist of decomposition products of the electrolyte, depend on the electrochemical stability of the ion conductor. Many electrolytes known are unstable against Li metal [81-84]. If high-voltage cathode materials are used to increase the power and energy density of the system, the electrolyte has to withstand potentials as a high as $5 \mathrm{~V}$. Although electrochemical stability of solid electrolytes has been shown to be much better than that of liquid organic blends [84], the long-term stability of a given solid at high cathode potentials or being in contact with Li metal is still one of the white areas future research has to tackle. Placing a very thin, artificial interlayer such as crystalline (or amorphous) $\mathrm{LiAlO}_{2}, \mathrm{LiTaO}_{3}, \mathrm{LiNbO}_{3}$ or even $\mathrm{Al}_{2} \mathrm{O}_{3}$ [85] at the cathode-electrolyte interface may increase chemical and electrochemical stability [21, 79, 86, 87]. These electronically insulating extra phases may, however, suffer from low intrinsic conductivity. They should be kept as thin as possible in order to not increase the corresponding charge transfer resistance. Paying attention to cost-effective processing techniques, able to implement such layers, is another key factor that might delay the breakthrough of large scale solid-state batteries.

Crossing the macroscopic boundaries and interfaces in a solid-state battery, which may change in chemical composition and morphology during the diverse operating conditions, represent the major hurdle the ions themselves have to master $[79,80,86]$. Impedance spectroscopy might be the method of choice to study internal resistances as a function of ageing. Considering the 'internal' barriers of the solid electrolyte a picture with similar complexity shows up. While, in ideal cases, AC conductivity spectroscopy is able to differentiate between bulk and grain boundary responses $[65,88]$, ion dynamics inside the lattice is often controlled by a highly irregular potential landscape. Hence, $\sigma_{\text {bulk }}$ and its activation energy $E_{\mathrm{a}, \mathrm{AC}}$ represent mean values. For many materials there is not a single diffusion mechanism or jump process at work but many processes run in parallel. Depending on the frequency range looked at, the weighed superposition of these processes yields $E_{\mathrm{a}, \mathrm{AC}}$. With the use of NMR the ion dynamics on the angstrom length scale can be (separately) characterized. Differences between results from NMR and AC conductivity spectroscopy [89-91], even if carried out in the $\mathrm{MHz}$ range where NMR operates [92], can be explained by the different motional correlation functions to which the methods are sensitive. The difference in results from NMR, driven by spin fluctuations, and conductivity spectroscopy, driven by electrical relaxation, has been the topic of many studies employing several models to assist in interpretation; see refs. [93-95] that serve as some of the early examples dealing with this aspect. Worth noting, NMR 


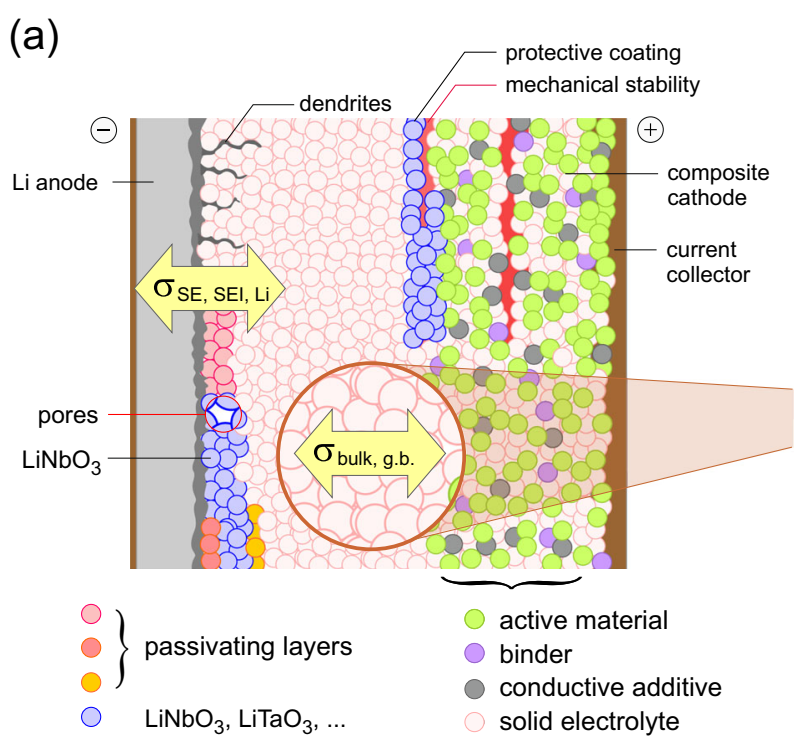

Fig. 2 Even if suitable candidates with high ionic conductivities have been identified, additional hurdles need to be overcome to realize a stable working all-solid-state battery. Stability concerns chemical and electrochemical robustness as well as mechanical solidity. For instance, the battery has to withstand mechanical stress originating from vehicle vibrations. (a) Schematic illustration of a solid-state battery with a ceramic solid electrolyte (SE), a Li metal anode and a composite cathode; see text for further explanation. While conductivity measurements are able to probe charge transfer across the macroscopic interfaces including the formation of passivating layers such as 'solid

is not only restricted to measure short-range motions but is also able to get access to long-range ion transport parameters [18]. This simply depends on the temperature window and on the effective resonance frequency used to monitor any changes in magnetization $[66,70,96]$.

\section{The NMR point of view: from fast to ultra-fast ion diffusivity}

In NMR relaxometry the spin-lattice relaxation rate $\left(R_{1}\right)$ is the central parameter that is recorded as a function of temperature [97]. It is a measure of how fast an ensemble of spins recovers from a non-equilibrium to the state of equilibrium defined by thermodynamics. At the beginning, i.e., in thermal equilibrium, the spins occupy the energetically distinct Zeeman levels according to Boltzman's distribution term. This distribution can be perturbed by exciting the spin systems with radio frequency pulses. Without any interactions of the spins with, e.g., phonos, electrons, spins of paramagnetic impurities, this non-equilibrium state generated is conserved for an extremely long time since spontaneous transitions are negligible. Apart from spin-phonon or spin-electron interactions, which usually control $R_{1}$ at low temperatures, $\mathrm{Li}$ ion hopping processes have a much larger effect on relaxation toward thermal equilibrium. In many (b)

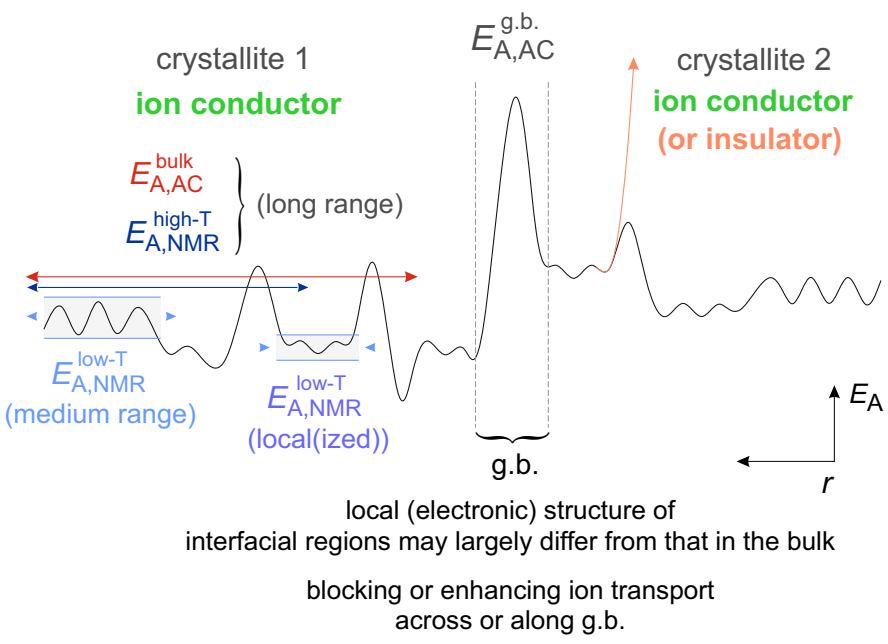

electrolyte interfaces' (SEI), NMR might help assist to probe bulk ion dynamics. (b) Complex potential landscape the ions are exposed to in a rigid lattice crystal structure; grain boundaries (g.b.) can largely influence through-going ion transport. Depending on the time-scale and length-scale to which NMR or AC conductivity spectroscopy are sensitive different activation energies are probed. The local (electronic) structure of the g.b. themselves may largely differ from the situation in the bulk. In the case of fast ion conductors these regions often block long-range ion transport

cases the purely diffusion-induced recovery can be well separated from non-diffusive effects if a wide temperature range is covered.

\subsection{Some basics of NMR relaxometry, 3D motion in solids}

To extract the $R_{1}$ rates the change of the magnetization $M=M_{z}$, which is the sum of the magnetic moments of the spins, has to be followed as a function of delay time. Usually, we use a saturation recovery pulse sequence [98] with a comb of closely spaced $\pi / 2$ pulses to prepare a defined non-equilibrium state (Fig. 3). From this state, which is given by $M_{z}\left(t_{d}=0\right)=0$, the amplitude of $M_{z}$ increases, in the simplest case exponentially, according to

$M_{z}(t) / M_{0}=1-\exp \left(-t_{d} / T_{1}\right)$

The rate $1 / T_{1} \equiv R_{1}$ depends on the fluctuations of internal fields sensed during ionic motions. They can be described by a so-called correlation function $G(t)$. According to the model introduced by Bloembergen, Purcell and Pound (BPP) [99], developed for random jump diffusion in three dimensions, $G(t)$ is assumed to be a single exponential

$G(t)=G(0) \exp \left(-|t| / \tau_{c}\right)$. 
(a)

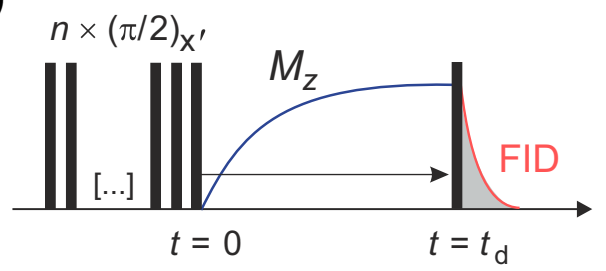

(b)



Fig. 3 (a) Pulse sequence to record spin-lattice relaxation rates in the laboratory frame of reference. (b) The spin-lock sequence used to acquire the rates $R_{1 \rho}$. During the locking pulse the transversal magnetization is exposed to the much weaker $B_{1}$ field. $M_{\rho}$ has do adapt itself to the new energetic situation. Hence, it decays toward a new, much smaller equilibrium amplitude that fits to $B_{1}$. FID: free induction decay

$\tau_{c}$ is the correlation time which, within a factor of the order of unity, equals the mean residence time $\tau$ between two successive jumps. The Fourier transform of $G(t)$, to which $R_{1}$ is related, is the spectral density function $J(\omega)$. It has a Lorentzian shape when $G(t)$ is an exponential. Most importantly, spin-lattice relaxation becomes effective when $J(\omega)$ has intensities at the resonance frequency $\omega_{0}$, which is in the $\mathrm{MHz}$ range [97].

$1 / T_{1} \equiv R_{1} \propto J\left(\omega_{0}\right) \approx G(0) \frac{2 \tau_{c}}{1+\left(\omega_{0} \tau_{c}\right)^{2}}$

The temperature dependence of $\tau_{c}$ in Eq. 3 is typically given by an Arrhenius relation

$\tau_{c}=\tau_{0} \exp \left(E_{\mathrm{A}} /\left(k_{\mathrm{B}} T\right)\right)$,

where $\tau_{0}$ is the pre-exponential factor and $E_{\mathrm{A}}$ the (mean) activation energy of the diffusion process. $T$ is the absolute temperature and $k_{\mathrm{B}}$ denotes Boltzmann's constant. Thus, for a given Larmor frequency $\omega_{0}$, the so-called diffusion-

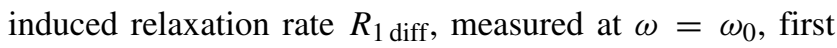
increases with increasing $T$ (low- $T$ range, $\omega_{0} \tau \gg 1$ ), passes through a maximum at a specific temperature $T_{\max }$ and decreases when temperature is further increased (high- $T$ range, $\left.\omega_{0} \tau \ll 1\right)$ ). Taking into account the frequency dependence of $R_{1}$ diff the behavior can be summarized as follows:

$R_{1 \text { diff }} \sim \exp \left(E_{\mathrm{a}}^{\text {low }-T} / k_{\mathrm{B}} T\right)$, if $T \gg T_{\max }\left(\omega_{0}\right)$

$R_{1 \text { diff }} \sim \omega_{0}^{\beta} \exp \left(-E_{\mathrm{a}}^{\mathrm{high}-T} / k_{\mathrm{B}} T\right)$, if $T \ll T_{\max }\left(\omega_{0}\right)$.

The lower the Larmor frequency the lower $T_{\max }\left(\omega_{0}\right)$. Especially in disordered materials $E_{\mathrm{a}}^{\text {high }-T}$ is larger than
$E_{\mathrm{a}}^{\text {low-T }}$ so that an asymmetric diffusion induced rate peak is observed. This behavior is in contrast to uncorrelated BPP behavior that leads to a symmetric $R_{1 \text { diff }}(1 / T)$ peak in the Arrhenius plot [97].

For BPP-type relaxation the exponent $\beta$ is 2 . For correlated motion, however, $1<\beta \leq 2$ is found. This is in line with several models developed to describe ion motions in disordered ion conductors where the ions are subjected to, e.g., Coulomb interactions in a heterogeneous potential landscape (see above). In particular, the coupling concept [90], the jump relaxation model [89], the dynamic structure model [100] or the assumption of a distribution of jump correlation times [101] predict exponents $\beta<2$. The parameter $\beta$, being thus a rough measure of deviation from uncorrelated motion, links the frequency dependence of $R_{1 \text { diff }}$ to the asymmetry of the peak, i.e., the two activation energies are related according to the simple relationship

$E_{\mathrm{a}}^{\text {low }-T}=(\beta-1) E_{\mathrm{a}}^{\mathrm{high}-T}$.

NMR relaxation entails an almost model independent access to diffusion parameters if $\tau_{c}$ is read out via the maximum condition, $\omega_{0} \tau_{c}=0.62$ (BPP behavior) [96]). With $\tau_{c} \approx \tau$ a microscopic self-diffusion coefficient can be calculated via the Einstein-Smoluchowski relation $D_{(\mathrm{NMR})}=$ $a^{2} /(6 \tau)$. $a$ denotes the average jump length which can be estimated from the lattice parameters of the crystals. $D$ values obtained from NMR can be compared with those estimated from AC conductivity measurements (see above). The conductivity $\sigma$, if recorded at low frequencies, is directly related to the long-range diffusion coefficient $D_{\text {cond. }}$ via the Nernst-Einstein relation

$D_{\text {cond. }}=\frac{\sigma k_{\mathrm{B}} T}{N q^{2}}$,

where $q$ denotes the charge and $N$ the number density of charge carriers. $\sigma T$ also follows Arrhenius behavior according to

$\sigma T=A \exp \left(-E_{\mathrm{a}, \mathrm{AC}} /\left(k_{\mathrm{B}} T\right)\right)$.

Finally, the self-diffusion coefficient $D$ is linked to $D_{\text {cond. }}$ via the relations $D_{\text {tracer }}=H_{r} D_{\text {cond. }}$ and $D_{\text {tracer }}=f D$ where $D_{\text {tracer }}$ is the so-called tracer diffusion coefficient. $H_{r}$ as well as $f$ represent the Haven ratio and the correlation factor connecting $D_{\text {tracer }}$ with $D$. This yields

$D_{\text {tracer }}=H_{r} \frac{\sigma k_{\mathrm{B}} T}{N q^{2}}=f a^{2} /(6 \tau)$

which gives

$\tau^{-1}=\left(H_{r} / f\right) \frac{6 k_{\mathrm{B}} T}{N q^{2} a^{2}} \cdot \sigma$

directly relating the motional correlation rate $\tau^{-1}$ available by NMR with $\sigma$. Assuming $H_{r} \approx 1$ and uncorrelated motion $(f=1)$ the ratio $H_{r} / f$ is almost 1 . 
Since $\omega_{0}$ is in the order of some MHz if external magnetic fields of several Tesla are used to measure $M_{z}\left(t_{d}\right)$, the corresponding residence time $\tau\left(T_{\max }\right)$ takes values in the ns regime. $\tau \approx 1$ ns roughly transforms into conductivities in the order of $10^{-3} \mathrm{~S} \mathrm{~cm}^{-1}$; the corresponding diffusioninduced rate peak $R_{1 \text { diff }}$ should desirably show up at or even below ambient temperature [18]. Replacing $\omega_{0}$ formally with a much smaller frequency in the $\mathrm{kHz}$ regime would shift the corresponding peak toward much lower temperatures. The measurement technique that can be used for this purpose is called spin-lock NMR where transversal spin-lattice relaxation is observed in the rotating frame of reference [102-106]: Immediately after a $\pi / 2$-pulse the magnetization $M_{\rho}$, pointing along the $\left(-y^{\prime}\right)$-axis, is locked by the magnetic field $B_{1}$ used to generate the excitation pulse (Fig. 3). The decay of $M_{\rho\left(-y^{\prime}\right)}$ is then probed as a function of the locking pulse length $t_{\text {lock. [107]. In the easi- }}$ est case $M_{\rho\left(-y^{\prime}\right)}$ follows an exponential decay governed by $R_{1 \rho}$. Because of $\omega_{0} \gg \omega_{1}$, spin-lock NMR is able to probe slower ionic motions. In many cases this enables access to the high- $T$ flank of the corresponding rate peak [97]. As for $R_{1}$, the slope of this flank describes long-range ionic motion through the crystal lattice.

In the following we will review some examples where both laboratory frame $\left(R_{1}\right)$ and rotating frame $\left(R_{1 \rho}\right)$ NMR relaxometry has been used to characterize ion dynamics in some of the most promising solid electrolytes. Emphasis is put on extracting Li jump rates and activation energies describing both short-range and long-range ion dynamics.

\subsection{D diffusion in lithium boron hydride: $\mathrm{LiBH}_{4}$}

Lithium boron hydride (see Fig. 4) is known as a reducing agent in organic synthesis. At room temperature the orthorhombic modification is stable that exhibits only a poor ion conductivity. While the $\mathrm{Li}$ ions are rather immobile on the $\mathrm{MHz}$ time scale, fast reorientations of the $\mathrm{BH}_{4}$ units are seen through ${ }^{11} \mathrm{~B},{ }^{1} \mathrm{H} \mathrm{NMR}$, and indirectly through the ${ }^{7} \mathrm{Li}$ spins $[108,109]$. At $T_{\text {hex./ortho }} \approx 381 \mathrm{~K}$ ortho- $-\mathrm{LiBH}_{4}$ reversibly transforms into its hexagonal modification, see Fig. 4, which may be used as solid electrolyte in a lithium battery (see ref. [110, 111] and Fig. 5). Hexa-LiBH 4 shows a layered structure that facilitates ion diffusion. The associated jump in ion conductivity is well documented by Maekawa et al. [112, 113]. At approximately $393 \mathrm{~K}$ the ionic conductivity is in the order of $2 \times 10^{-3} \mathrm{~S} \mathrm{~cm}^{-1}$ and $E_{a}$ turns out to be ca. $0.51 \mathrm{eV}$. These parameters are in excellent agreement with what has been found by ${ }^{7} \mathrm{Li} \mathrm{NMR}$ relaxometry carried out at temperatures above $T_{\text {hex./ortho }}$, see Fig. 4(b).

Above the phase transition temperature, the static ${ }^{7} \mathrm{Li}$ NMR line is drastically narrowed because of fast $\mathrm{Li}$ exchange processes that average $\mathrm{Li}-\mathrm{Li}$ homonuclear dipole interactions of the $3 / 2$-spins. This corroborates that the relaxation rate peaks seen in the hexagonal regime are due to extremely fast $\mathrm{Li}^{+}$translational motions. At $T_{\max } \approx 450 \mathrm{~K}$ the jump rate $\tau^{-1}$ is in the order of $10^{9} \mathrm{~s}^{-1}$. From conductivity spectroscopy, $\sigma \approx 14 \mathrm{mS} \mathrm{cm}^{-1}$ is obtained which is in reasonable agreement with results from NMR [113]. Worth noting, the frequency dispersion of the high- $T$ flank of the rate peaks indicates spatially confined $\mathrm{Li}$ ion diffusion. Indeed, ${ }^{6} \mathrm{Li} \mathrm{NMR}$ spin-lattice relaxation reveals the same characteristics which can be interpreted as $2 \mathrm{D}$ ionic motions $[70,114,115]$ in the layered structure of $\mathrm{LiBH}_{4}$ [116]. As the ${ }^{6} \mathrm{Li}$ nucleus (spin-quantum number $I=1$ ) is subject to much less dipolar and quadrupolar interactions it can be described as a quasi spin-1/2 nucleus. This circumstance is important for the meaningful use of $2 \mathrm{D}$ relaxation models (a)

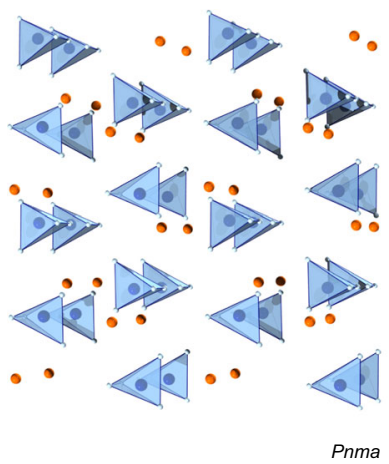

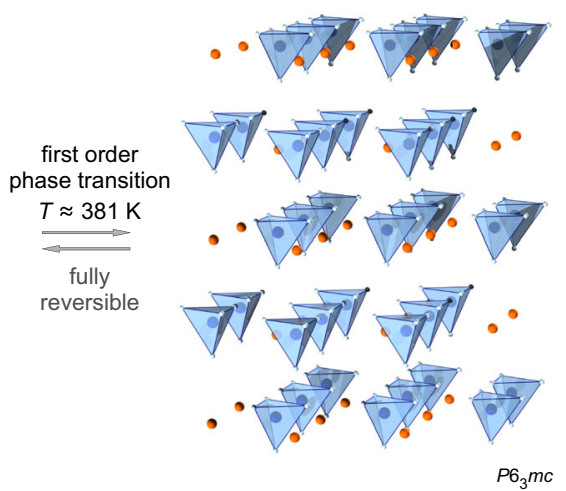

(b)

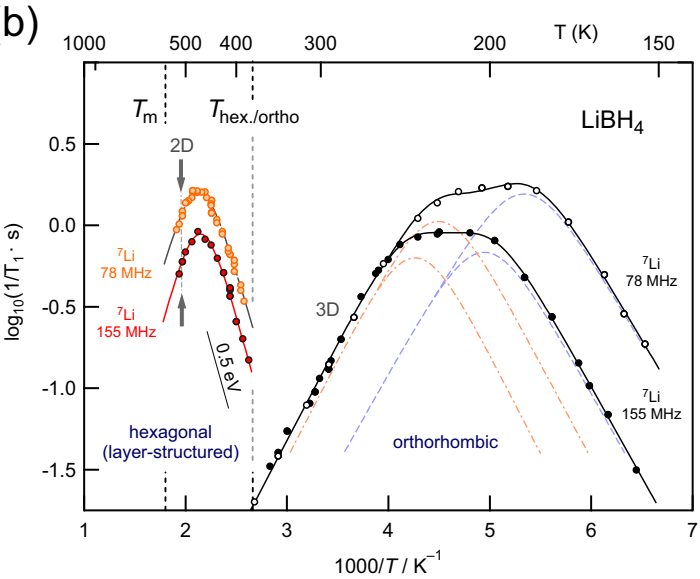

Fig. 4 (a) $\mathrm{LiBH}_{4}$ exists in two modifications below its melting point of $548 \mathrm{~K}$. Below $381 \mathrm{~K}$ the poorly conducting orthorhombic phase is stable, whereas at elevated $T$ the layered modification is available. Through variable-temperature and variable-frequency ${ }^{7} \mathrm{Li}$ and
${ }^{6} \mathrm{Li} \mathrm{NMR}$ relaxometry $\mathrm{Li}$ ion diffusion in the hexagonal form has been shown to be $2 \mathrm{D}$ in nature. In (b) the rate $R_{1 \text { diff }} \equiv 1 / T_{1}$ is plotted vs. the inverse temperature; $R_{1}$ diff was recorded at two different Larmor frequencies as indicated 
(a)

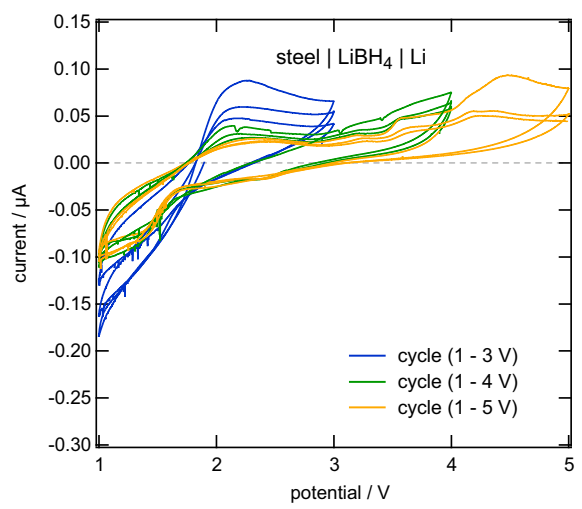

(b)

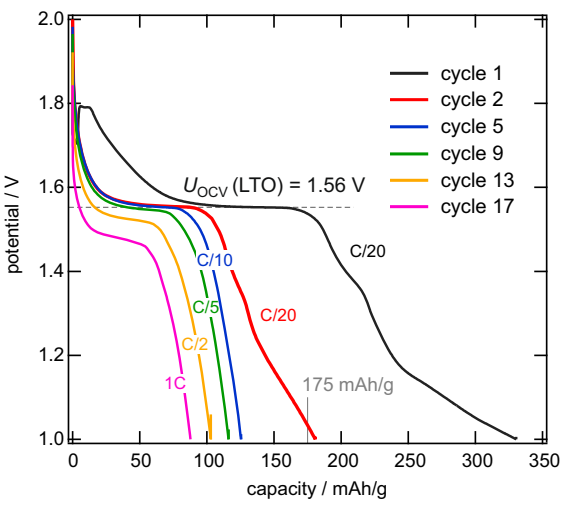

(c)

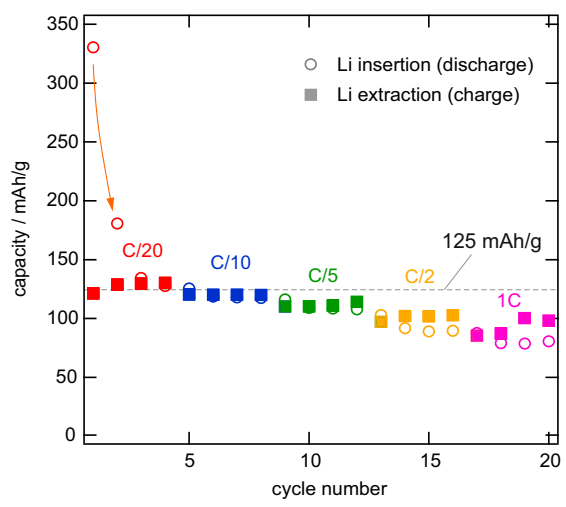

Fig. $5 \mathrm{LiBH}_{4}$ as solid electrolyte: (a) electrochemical stability tested via cyclic voltammetry in the potential range from $1 \mathrm{~V}$ to $5 \mathrm{~V}$, the scan rate was $0.05 \mathrm{mV} \mathrm{s}^{-1}$ (BioLogic VMP3 multichannel potentiostat/galvanostat). (b) Discharge curves of a $\mathrm{Li}\left|\mathrm{LiBH}_{4}\right| \mathrm{LTO}$ cell prepared by cold pressing of the battery components. The cell was placed in an airtight Swagelok cell and galvanostatically cycled with potential limitation between $2 \mathrm{~V}$ and $1 \mathrm{~V}$ at $393 \mathrm{~K}$; discharge refers to the reaction $\mathrm{Li}_{4} \mathrm{Ti}_{5} \mathrm{O}_{12}+3 \mathrm{Li}^{+}+3 \mathrm{e}^{-} \rightarrow \mathrm{Li}_{7} \mathrm{Ti}_{5} \mathrm{O}_{12}$ (c) Discharge capacities obtained at different $\mathrm{C}$-rates and cycles

be reached without any remarkable overpotentials seen in the discharge curves; this is in agreement with recent studies by Sveinbjörnsson et al. [111]. The drastic fade in capacity occurring after the first cycles has to be looked for in electrochemical side reactions and the formation of interface layers (at the cathode side). Further fading because of increased C-rates might be traced back to kinetic reasons. Nevertheless, capacities in the order of $125 \mathrm{mAh} \mathrm{g}^{-1}$ at $\mathrm{C} / 10$ mark a starting point for further research. Pure $\mathrm{LiBH}_{4}$ can also be replaced with $\mathrm{LiBH}_{4}$ :LiI solid solutions; the incorporation of LiI stabilizes the highly conducting hexagonal modification of $\mathrm{LiBH}_{4}$ down to lower temperatures $[111,113]$.

\subsection{Garnet-type oxides: cation-stabilized cubic LLZO and LLZMO}

The chemical robustness and high ionic, but negligible electronic, conductivities of various garnet-type oxides [19] are beneficial for the design of all-solid-state lithium batteries with metal anodes. Regarding $\mathrm{Li}_{7} \mathrm{La}_{3} \mathrm{Zr}_{2} \mathrm{O}_{12}$, its tetragonal modification is a moderate Li ion conductor [119]. The replacement of $\mathrm{La}$ and $\mathrm{Zr}$ ions with isovalent or aliovalent cations greatly affects, however, (i) the defect chemistry, (ii) the crystal structure parameters and (iii) also the Li content of the garnets [40, 120-122]. These variations lead to a series of oxides that may largely differ in ionic conductivities [19]. Furthermore, grain boundary structures and distinct morphologies because of the different preparation routes used influence overall ion transport, too [19].

If trivalent cations such as $\mathrm{Al}^{3+}$ or $\mathrm{Ga}^{3+}$ are used to replace the $\mathrm{Li}$ ions by a few percent, vacant sites in the $\mathrm{Li}$ sublattice are introduced. The small change in lattice constants as well as the exitance of vacant $\mathrm{Li}$ sites immediately 
causes the tetragonal form to adopt cubic symmetry [123]. The $\mathrm{Li}$ ions, which originally have occupied the $16 \mathrm{f}$ and $32 \mathrm{~g}$ sites in tetragonal LLZO, now reside on the 96h positions which corresponds to the empty 16e site in tetra-LLZO; ions on $8 \mathrm{a}$ in tetra-LLZO now occupy the $24 \mathrm{~d}$ position in the cubic polymorph [123]. In Al-stabilized cubic-LLZO the trivalent "dopants" also reside on the $24 \mathrm{~d}$ and $96 \mathrm{~h}$ sites [124]. Since many of these sites are vacant, facile Li ion diffusivity can be expected; indeed, Al-bearing c-LLZO belongs to the fastest oxide ion conductors known [39]. The arrangement of the Li sites is sketched in Fig. 6, see also ref. [118]. Li diffusion along the 3D 24d-96h-24d diffusion pathways (see Fig. 7(c)) is expected to largely depend on the Li content, the dopant distribution as well as the kind and number of defects, mainly vacancies, in the vicinity of the $\mathrm{Li}$ ions [22]. Thus, we expect a heterogeneous potential landscape with many correlated jump processes running in parallel and for which the activation energies for forward and backward jumps will also differ. The immobile trivalent dopant ions may easily block some of the fast diffusion pathways, thus clearly interacting with the mobile charge carriers.

Through conductivity spectroscopy the average activation energy for long-range ion transport in Al-stabilized c-LLZO is given by ca. $0.35 \mathrm{eV}$ [39]. Similar values have also been deduced from NMR relaxometry (see below and ref. [39]); the temperature dependence of the rates $R_{1}$ diff and $R_{1} \rho$ diff, however, clearly reveals complex lengthscale dependent ion dynamics, see Fig. 7. While in the limit $\omega_{0} \tau \gg 1$ the flank of $R_{1 \operatorname{diff}}(1 / T)$ is governed by only $0.12 \mathrm{eV}, R_{1} \rho$ diff data in the range $\omega_{1} \tau \ll 1$ points to larger (mean) barriers the ions have to surmount. Other garnets, not necessarily those with trivalent cations on $24 \mathrm{~d}$ and $96 \mathrm{~h}$, have to be characterized by the same $R_{1 \text { diff }}$ behavior [118], see Fig. 7(b).

Another almost universal feature of $R_{1 \rho \text { diff }}$ in the case of cation-disordered LLZO is the broad relaxation rate peak that spans an extraordinary large temperature range [39, 117]. It is definitely the result of a superposition of distinct local and long-range jump processes. This is in contrast to crystal structures with similarly high ionic diffusivity but with no foreign ions on the Li sites [118]. As an example, in Fig. 7 the diffusion-induced NMR relaxation rates of polycrystalline $\mathrm{Al}$-free $\mathrm{Li}_{6.5} \mathrm{La}_{3} \mathrm{Zr}_{1.75} \mathrm{Mo}_{0.25} \mathrm{O}_{12}$ (LLZMO) are shown. In LLZMO the Li-sublattice is not influenced by blocking dopant ions and the $R_{1} \rho$ diff data can be approximated with two individual rate peaks. These peaks represent two almost similarly activated jump processes that differ in the pre-exponential factor of the underlying Arrhenius equation. From the peak, which is shifted toward higher temperatures, at $T_{\max }=315 \mathrm{~K}$ a jump rate of $4.2 \times$ $10^{5} \mathrm{~s}^{-1}$ is obtained. This translates, using the EinsteinSmoluchowski equation, into a self-diffusion coefficient $D$ of $1.9 \times 10^{-11} \mathrm{~cm}^{2} \mathrm{~s}^{-1}$ [118].

The jump rate obtained via spin-lock NMR agrees well with that directly measured through ${ }^{7} \mathrm{Li}$ stimulated (spinalignment) echo (SAE) NMR measurements [118]. With SAE NMR Li jumps between electrically inequivalent $\mathrm{Li}$ sites are probed. For the present case, this principle means that the garnet sites $24 \mathrm{~d}$ and $96 \mathrm{~h}$ are definitely involved in Li jump diffusion. Note that the SAE NMR method [38, 66$70,96,126-131]$ is able to sense very low exchange rates $<10^{5} \mathrm{~s}^{-1}$.

\subsection{Phosphates with NASICON structure:}

\section{$\mathbf{L i}_{1.5} \mathrm{Al}_{0.5} \mathrm{Ti}_{1.5} \mathrm{PO}_{4}$}

The titanium phosphate $\mathrm{Li}_{1+x} \mathrm{Al}_{x} \mathrm{Ti}_{2-x} \mathrm{PO}_{4}$ with $x=0.5$ is one of the most promising compounds of the LATP family with ionic conductivities high enough to realize solid-state lithium batteries [65]. Its electrochemical stability against Li metal and other high-voltage cathode materials needs to be ensured by protective coatings. Via NMR we have investigated bulk ion dynamics in LATP with the composition $\mathrm{Li}_{1.5} \mathrm{Al}_{0.5} \mathrm{Ti}_{1.5} \mathrm{PO}_{4}$ [125]. In contrast to a recent NMR study [132], the sample investigated by us was prepared by a novel sol-gel method that allowed precisely controlling the composition and morphology of the product


Fig. 6 Illustration of some of the elementary hopping steps of ion hopping in garnet-type $\mathrm{Li}_{7} \mathrm{La}_{3} \mathrm{Zr}_{2} \mathrm{O}_{12}$ with cubic symmetry $(I a \overline{3} d)$. The 96h-24d exchange leads to correlated 3D diffusion (a); larger activation energies are expected for jumps between the atom-split sites $(96 \mathrm{~h}-48 \mathrm{f}-96 \mathrm{~h})$, see $(\mathbf{b})$. In c $=(\mathbf{c})$ strictly localized movements are indicated that are expected to be controlled by lower activation energies 
(a)



(b)

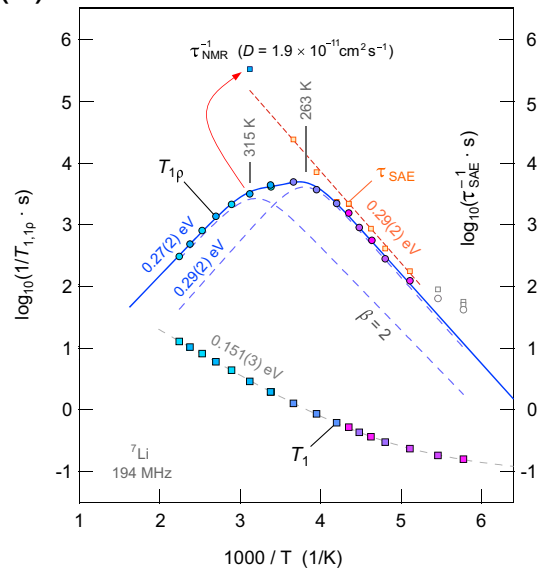

(c)

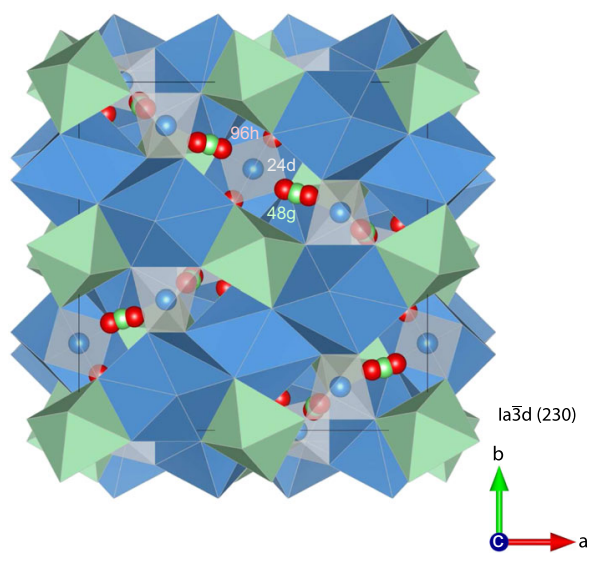

Fig. 7 (a) ${ }^{7} \mathrm{Li}$ NMR spin-lattice relaxation rates of Al-containing and Ga-bearing $\mathrm{Li}_{7} \mathrm{La}_{3} \mathrm{Zr}_{2} \mathrm{O}_{12}$ (LLZO). (b) Arrhenius plot of the ${ }^{7} \mathrm{Li}$ SLR NMR rates of crystalline $\mathrm{Li}_{6.5} \mathrm{La}_{3} \mathrm{Zr}_{1.75} \mathrm{Mo}_{0.25} \mathrm{O}_{12}(194 \mathrm{MHz}$, $33.3 \mathrm{kHz}$ locking freuency). The continuous line represents the sum of two single rate peaks shown each with a dashed line. The dasheddotted line drawn through the $T_{1}^{-1}$ data points is a combination of an

obtained. Importantly, the low sintering temperatures particularly prevent $\mathrm{Li}$ loss during the final annealing step.

Rhombohedral $\mathrm{Li}_{1.5} \mathrm{Al}_{0.5} \mathrm{Ti}_{1.5} \mathrm{PO}_{4}$ crystallizes with the space group $\mathrm{R} \overline{3} \mathrm{c}$ and adopts the NASICON structure $(\mathrm{Na}$ super-ionic conductor, $\mathrm{Na}_{1+x} \mathrm{Zr}_{2} \mathrm{Si}_{x} \mathrm{P}_{3-x} \mathrm{O}_{12}(0<x<$ $3)$ ). It is composed of alternating, corner-sharing $\left[\mathrm{PO}_{4}\right]$ tetrahedra and $\left[\mathrm{TiO}_{6}\right]$ octahedra in which $\mathrm{Li}$ can occupy interstitial sites such as the M1(6b) site (see Fig. 8(c)). If starting from $\mathrm{LiTi}_{2} \mathrm{PO}_{4}$ the $\mathrm{Ti}^{4+}$ are consecutively replaced by lower valent $\mathrm{Al}^{+3}$ ions, for the reason of charge neutrality additional Li ions are inserted that occupy the M3 voids (Fig. 8(c), [134]). This enhancement of the charge carrier concentration directly affects Li ion dynamics. Indeed, at room temperature an already fully motionally narrowed ${ }^{7} \mathrm{NMR}$ line is recorded that is characterized by a quadrupolar powder pattern with a (mean) coupling constant of 45.4 $\mathrm{kHz}$, see Fig. $8 \mathrm{~b}=(\mathrm{b})$. The sharp (residual) powder pattern emerges from a featureless quadrupole hump with low intensity seen at very low $T$.

Li NMR relaxometry corroborates the high Li diffusivity indicated by line shape measurements; the rates $R_{1}$ diff and $R_{1} \rho$ diff when plotted vs the inverse temperature reveal several distinct peaks that point to multiple Li jump processes in $\mathrm{Li}_{1.5} \mathrm{Al}_{0.5} \mathrm{Ti}_{1.5} \mathrm{PO}_{4}$ [125]. The first $R_{1 \rho \text { diff }}(1 / T)$ peak shows up at ca. $182 \mathrm{~K}$ (Fig. 8(a)). Thus, well below ambient temperature the jump rate has already reached values in the order of $10^{5} \mathrm{~s}^{-1}$. For comparison, for LLZMO the first maximum, at a similar locking frequency, is seen at $263 \mathrm{~K}$ [118]. The corresponding $R_{1 \text { diff }}(1 / T)$ peak of LATP is found at ca. $333 \mathrm{~K}$. A second pair of relaxation rate peaks is seen at somewhat higher $T$. The dashed lines in Fig. 8(a) represent so-called joint or global fits that simultaneously reproduce
Arrhenius fit with a power-law fit that takes into account background relaxation at low $T$. For comparison, decay rates obtained from ${ }^{7} \mathrm{Li}$ stimualted echo NMR, able to measure slower exchange processes, are also shown. (c) Cubic crystal structure $(\mathrm{Ia} \overline{3} \mathrm{~d})$ of $\mathrm{Li}_{7} \mathrm{La}_{3} \mathrm{Zr}_{2} \mathrm{O}_{12}$. Figures adapted from refs. [39, 117, 118]

the peak in the laboratory and in the rotating frame. For the two pairs of relaxation processes activation energies were found to be rather small $(0.174 \mathrm{eV}$ and $0.160 \mathrm{eV})$ [125]. Such low values are in agreement with a diffusion pathway that involves interstitial positions as has been the outcome of recent calculations performed by Lang et al. using density functional theory [135].

The differences in $T_{\max }$ might be explained by the pre-exponential factors $\tau_{0}$ determining the two underlying Arrhenius relations. Although thermally activated with rather equal activation energies the configurational entropy terms may differ for the two pathways. In LATP Li ions that are (i) displaced from their original sites in Al-free LTP or (ii) trapped in the neighbourhood of $\mathrm{Al}$ cations might have access to a different number of available sites to jump to. As in the case of Al-stabilized LLZO, the low- $T$ flank of the $R_{1 \text { diff }}(1 / T)$ is characterized by an even lower activation energy $(0.11 \mathrm{eV})$ than found with $R_{1} \rho \operatorname{diff}(1 / T)$ in the limit $\omega_{0} \tau \gg 1$. While for the rotating-frame data $\beta=2$ well reproduces the peak, for those measured in the lab frame the small slope causes $\beta$ to adopt a value of 1.66. Localized M1M3 exchange processes or within-site motions in the rather large and distorted M3 voids might be responsible for this behavior [135], which would be in analogy to the caged $\mathrm{Li}$ ion dynamics in the split-site $96 \mathrm{~h}-48 \mathrm{~g}-96 \mathrm{~h}$ in LLZO, see the discussion above.

In Fig. 8(d) the NMR rate peaks of LATP are compared with those of garnet-type c- $\mathrm{Li}_{6.6} \mathrm{La}_{3} \mathrm{Zr}_{1.6} \mathrm{Ta}_{0.4} \mathrm{O}_{12}$ [125] and one of the best ion conducting sulfides: $\mathrm{Li}_{6} \mathrm{PS}_{5} \mathrm{Br}$, which, in terms of conductivity, is comparable to $\mathrm{Li}_{10} \mathrm{GeP}_{2} \mathrm{~S}_{12}$, see above [35, 62]. Since the locking frequencies used are comparable, the lower the temperature at which the 
(a)
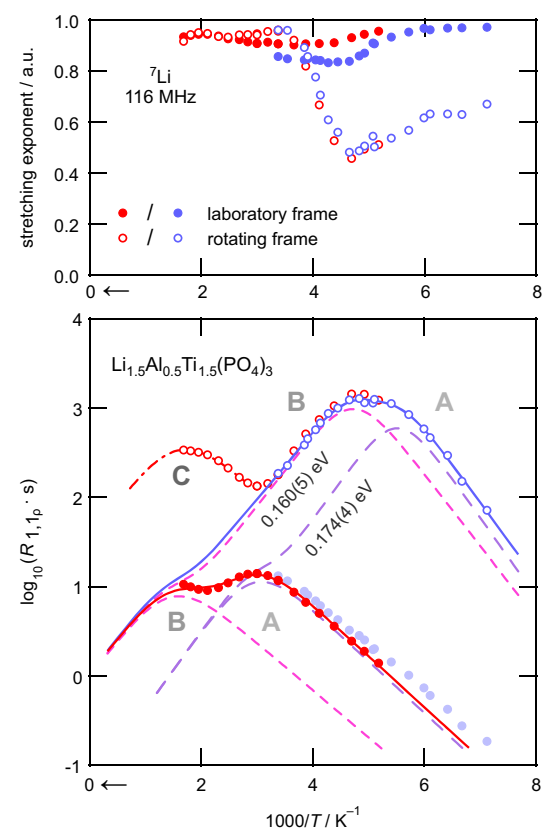

(b)

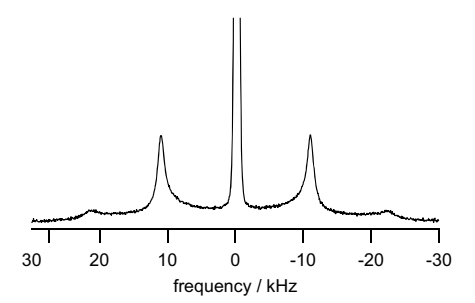

(c)

(d)

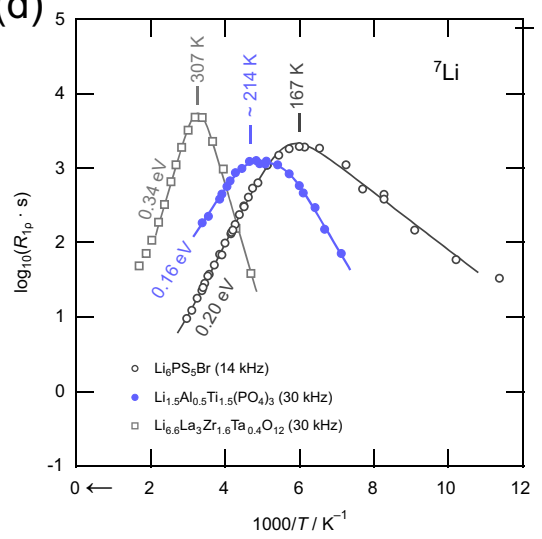

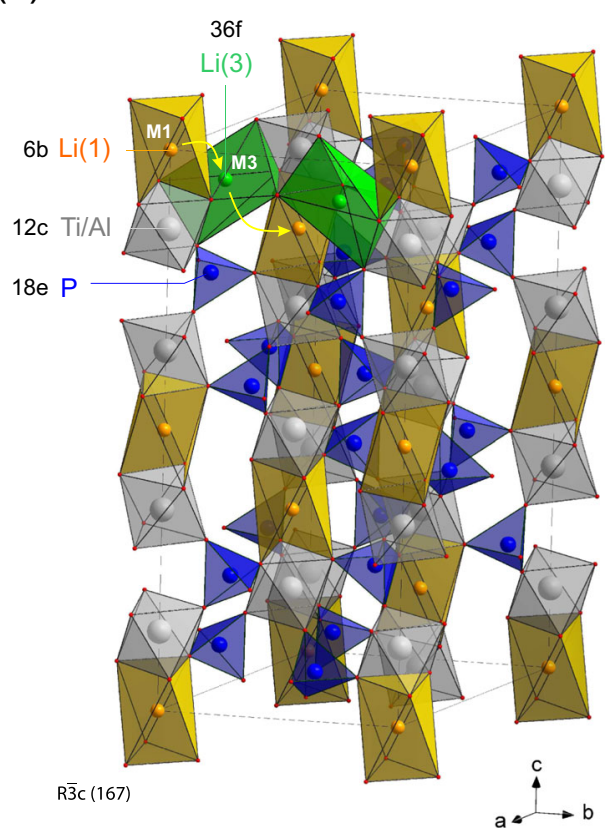

Fig. 8 (a) ${ }^{7} \mathrm{Li}$ NMR spin-lattice relaxation rates $R_{1 \text { diff }}$ and $R_{1} \rho$ diff of $\mathrm{Li}_{1.5} \mathrm{Al}_{0.5} \mathrm{Ti}_{1.5} \mathrm{PO}_{4}$ recorded at $116 \mathrm{MHz}$ and $30 \mathrm{kHz}$. In the upper graph the stretching exponents of the magnetization transients are given; values smaller than 1 show deviations from single exponential behavior: $M_{\rho}\left(t_{\text {lock }}\right) \propto \exp \left(-\left(t_{\text {lock }} / T_{1 \rho}\right)^{\gamma_{\rho}}\right)$. The smallest values of $\gamma_{\rho}$ are found when the rate $R_{1} \rho$ diff passes through the maxima. Figure adapted from ref. [125]. (b) Quadrupole powder pattern of a ${ }^{7} \mathrm{Li}$ NMR static spectrum recorded at $295 \mathrm{~K}$; the intensities next to the

diffusion-induced rate peak shows up, the higher the diffusivity seen via time-domain NMR. Thus, $\mathrm{Li}$ ion selfdiffusion increases in the order c- $\mathrm{Li}_{6.6} \mathrm{La}_{3} \mathrm{Zr}_{1.6} \mathrm{Ta}_{0.4} \mathrm{O}_{12}<$ $\mathrm{Li}_{1.5} \mathrm{Al}_{0.5} \mathrm{Ti}_{1.5} \mathrm{PO}_{4}<\mathrm{Li}_{6} \mathrm{PS}_{5} \mathrm{Br}$. While LATP adopts an intermediate position, ultra-fast $\mathrm{Li}$ ion exchange is seen for the sulfide [133].

\subsection{Sulfides: $\mathrm{Li}_{6} \mathrm{PS}_{5} \mathrm{Br}$ and $\mathrm{Li}_{7} \mathrm{P}_{3} \mathrm{~S}_{11}$}

The NMR rate peaks $R_{1 \text { diff }}(1 / T)$ and $R_{1 \rho \operatorname{diff}}(1 / T)$ of $\mathrm{Li}_{6} \mathrm{PS}_{5} \mathrm{Br}$ are shown in Fig. 9. The rates recorded at a locking frequency of $14 \mathrm{kHz}$ pass through a rate maximum at temperatures as low as $167 \mathrm{~K}$. In the limit $\omega_{1} \tau \gg 1$ the rates turned out to be independent of frequency which points to 3D diffusion. The asymmetric shape of the peaks with its lower slope on the high- $T$ side $\left(\omega_{1} \tau \ll 1\right)$ clearly reveals correlated motions because of the influence of disorder on the angstrom length scale combined with Coulomb interactions. From a global fit, represented in Fig. 9(b) by the solid line, an activation energy as alow as $0.2 \mathrm{eV}$ is obtained [133]. It represents translational long-range Li ion dynamics; the corresponding value on the low- $T$ side is only 0.08 $\mathrm{eV}$, which is indicative for local(ized) ion dynamics. central line originate from the interaction of the quadrupole moment of ${ }^{7} \mathrm{Li}$ with the average electric field gradient the ions are exposed to in LATP. Assuming axial symmetry of the corresponding tensor, the spikes at $\pm 11.35 \mathrm{kHz}$ yield a coupling constant of $45.4 \mathrm{kHz}$. (c) Crystal structure of LATP; the M1 and M3 sites form 3D zig-zag pathways the ions can use to migrate through the crystal. For the sake of clarity only 2 (adjacent) M3 sites have been filled. $\mathrm{Al}$ and Ti cations share the $12 \mathrm{c}$ site. (d) Comparison with results from other electrolytes

In line with the $R_{1 \rho \operatorname{diff}}(1 / T)$ data, the rate peaks measured with the saturation recovery sequence show up at temperatures well below ambient. In the limit $\omega_{1} \tau \gg 1$ the rates $R_{1}$ diff sense the same local hopping as $R_{1} \rho$ diff does. At $T=T_{\max }$, with $\omega_{0} / 2 \pi=116 \mathrm{MHz}$ we end up with a diffusion coefficient in the order of $7.6 \times 10^{-8} \mathrm{~cm}^{2} \mathrm{~s}^{-1}$ at $263 \mathrm{~K}$. This value is obtained if we assume a mean jump distance of ca. $2.5 \AA$. $D$ translates into a Li ion conductivity in the order of $10^{-2} \mathrm{~S} \mathrm{~cm}^{-1}$ which definably makes $\mathrm{Li}_{6} \mathrm{PS}_{5} \mathrm{Br}$ an ultrafast ionic conductor with a liquid-like diffusion behavior [133].

The finding that $\mathrm{Li}_{6} \mathrm{PS}_{5} \mathrm{Br}$ offers rapid $\mathrm{Li}$ ion exchange processes was corroborated by ${ }^{7} \mathrm{Li} \mathrm{NMR}$ line width studies (see Fig. 9(a)) and ${ }^{6} \mathrm{Li}$ NMR relaxometry measurements in the lab frame, see Fig. 9(b). Due to the weaker electric and magnetic interactions of the ${ }^{6} \mathrm{Li}$ spins the absolute rates $R_{1 \text { diff }}$ are shifted toward lower values. Because of the lower resonance frequency used to acquire the $R_{1 \operatorname{diff}}(1 / T)$ peak in the case of ${ }^{6} \mathrm{Li}$ the rate maximum shows up at lower $T_{\max }$, as expected [133].

As is seen in Fig. 9a $=(a)$, motional line narrowing reveals that while $\mathrm{Li}$ self-diffusion in $\mathrm{Li}_{6} \mathrm{PS}_{5} \mathrm{Br}$ is the fastest, the incorporating of $\mathrm{Cl}$ and $\mathrm{Br}$ anions in general lead to a jump in $\mathrm{Li}$ ion diffusivity. The lower the onset temper- 
(a)

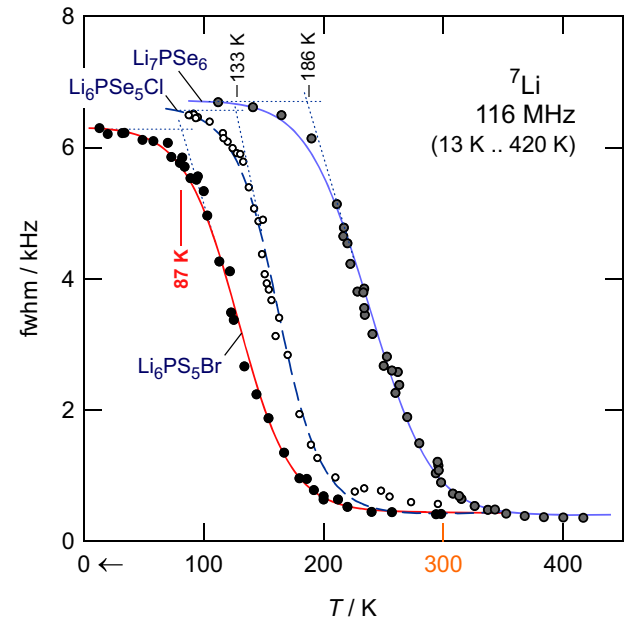

Fig. 9 (a) ${ }^{7} \mathrm{Li} \mathrm{NMR}$ motional line narrowing of $\mathrm{Li}_{7} \mathrm{PSe}_{6}, \mathrm{Li}_{6} \mathrm{PSe}_{5} \mathrm{Cl}$, and $\mathrm{Li}_{6} \mathrm{PS}_{5} \mathrm{Br}$ observed over a temperature range from $13 \mathrm{~K}$ to 420 $\mathrm{K}$. The almost independent line width in the rigid-lattice allows for a direct comparison of the narrowing curves. As is indicated, the introduction of $\mathrm{Cl}$ and $\mathrm{Br}$ anions into the structure shifts the onset of line narrowing toward lower temperatures. This means $\mathrm{Li}$ ion diffusivity gets faster in the following order: $\mathrm{Li}_{7} \mathrm{PSe}_{6}<\mathrm{Li}_{6} \mathrm{PSe}_{5} \mathrm{Cl}<\mathrm{Li}_{6} \mathrm{PS}_{5} \mathrm{Br}$. Obviously, the mismatch in ionic radii as well as polarization effects immensely influence Li self-diffusion resulting in extraordinary low

ature of motional narrowing, the faster Li self-diffusivity. Line narrowing results from averaging of (homonuclear) dipole-dipole interactions due to sufficiently fast hopping processes. At very low temperatures ion diffusivity can be regarded as frozen with respect to the NMR time scale. With increasing temperature, however, Li diffusivity rapidly increases. When mean jump rates in the order of the low- $T$ line width are reached, this is ca. 6 to $7 \mathrm{kHz}$ in the present case (cf. Fig. 9(a)), the line starts to narrow. Therefore, we conclude that at approximately $90 \mathrm{~K}$ the jump rate in $\mathrm{Li}_{6} \mathrm{PS}_{5} \mathrm{Br}$ has already reached values in the order of $10^{4}$ to $10^{5} \mathrm{~s}^{-1}$. For other solid electrolytes, such results are usually seen at $200 \mathrm{~K}$ and higher. It is evident that the replacement of $\mathrm{S}$ or $\mathrm{Se}$ anions with $\mathrm{Cl}$ or $\mathrm{Br}$ differing in ionic radii causes local strain that may facilitate ionic diffusion [133]. This mismatch in size combined with the different polarizabilities of the halogen ions could serve as an explanation of the enhancement seen when going from $\mathrm{Li}_{7} \mathrm{PS}(\mathrm{e})_{6}$ to $\mathrm{Li}_{6} \mathrm{PS}_{5} \mathrm{Br}$.

As a last example of a fast ion conductor, which plays an increasing role in all-solid state batteries, $\mathrm{Li}_{7} \mathrm{P}_{3} \mathrm{~S}_{11}$ is presented. If at hand in the form of a glass ceramic, the NMR spin-lattice relaxation behavior at both frequencies in the $\mathrm{MHz}$ and $\mathrm{kHz}$ range turned out to be rather complex. As an example, in Fig. 10 the ${ }^{6} \mathrm{Li}$ and ${ }^{7} \mathrm{Li}$ NMR relaxation rates are shown [64]. The rates recorded in the laboratory frame, $R_{1}$, show Arrhenius-type flanks from which a series
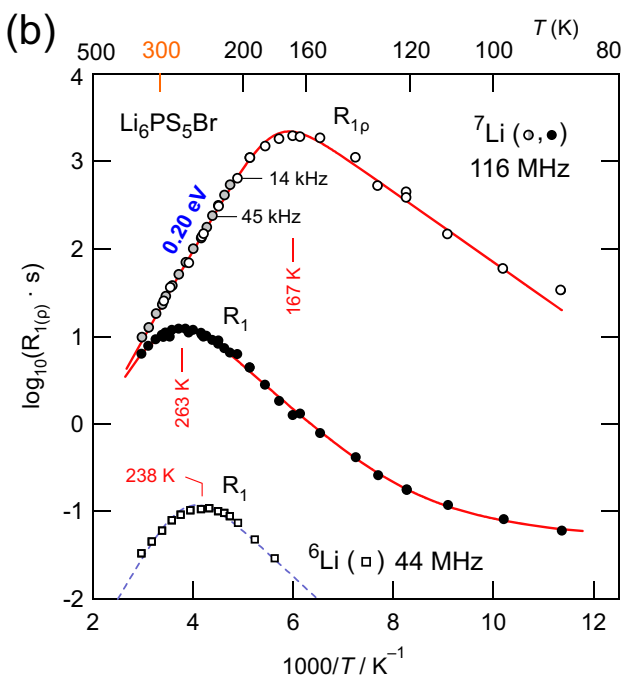

onset temperatures for the Br-bearing compound. (b) ${ }^{7} \mathrm{Li}$ NMR rate peaks $R_{1 \text { diff }}(1 / T)$ and $R_{1} \rho$ diff $(1 / T)$ of $\mathrm{Li}_{6} \mathrm{PS}_{5} \mathrm{Br}$ that were recorded in both the rotating frame and the laboratory frame. For comparison, also the analogous ${ }^{6} \mathrm{Li}$ NMR data are shown. From the high- $T$ flank an activation energy for long-range Li ion diffusion of only $0.2 \mathrm{eV}$ is obtained that perfectly agrees with the low onset temperature seen in line shape studies. See text for further explanation. Figure adapted from ref. [133]

of activation energies in different ranges of temperature were deduced. For example, the ${ }^{7} \mathrm{Li}$ NMR rate $R_{1}$ starts to be influenced by dynamic processes at temperatures being larger than $250 \mathrm{~K}$. Then the rate runs through a peak area with unusual shape. Usually the high- $T$ side of a given relaxation peak is expected to be characterized by an activation energy larger than that of the low- $T$ side. In the present case, this is not fulfilled. A similar behavior is seen if the ${ }^{6} \mathrm{Li}$ nucleus is used to follow spin-lattice relaxation. The anomalous shape of the rate peaks can be explained if we simply assume a number of dynamic phenomena, including also rotational motions of the P-S units, to be responsible for overall longitudinal relaxation.

Indeed, on the $\mathrm{kHz}$ range, even the magnetization transients cannot be represented with a single (stretched) exponential. Only a combination of three decay functions is able to properly describe the decay of $M_{\rho}$ as a function of locking frequency, see Fig. 10(b). In the upper part of the figure some selected transients $M_{\rho}$ are shown, in the lower part the transient recorded at $226 \mathrm{~K}$ and a locking frequency of 25 $\mathrm{kHz}$ is displayed together with the fit used to parameterize its shape; $\gamma_{i}$ with $i=1,2,3$ denote the stretching exponents in $M_{\rho, i}\left(t_{\text {lock }}\right) \propto \exp \left(-\left(t_{\text {lock }} / T_{1 \rho}\right)^{\gamma_{i}}\right)$. Interestingly, the fast decay at short locking times $t_{\text {lock }}$ resembles that of spin-spin relaxation behavior. Further NMR experiments making use of ${ }^{31} \mathrm{P}$ spin-lattice relaxation may throw some light on the dynamic situation in $\mathrm{Li}_{7} \mathrm{P}_{3} \mathrm{~S}_{11}$. 
(a)

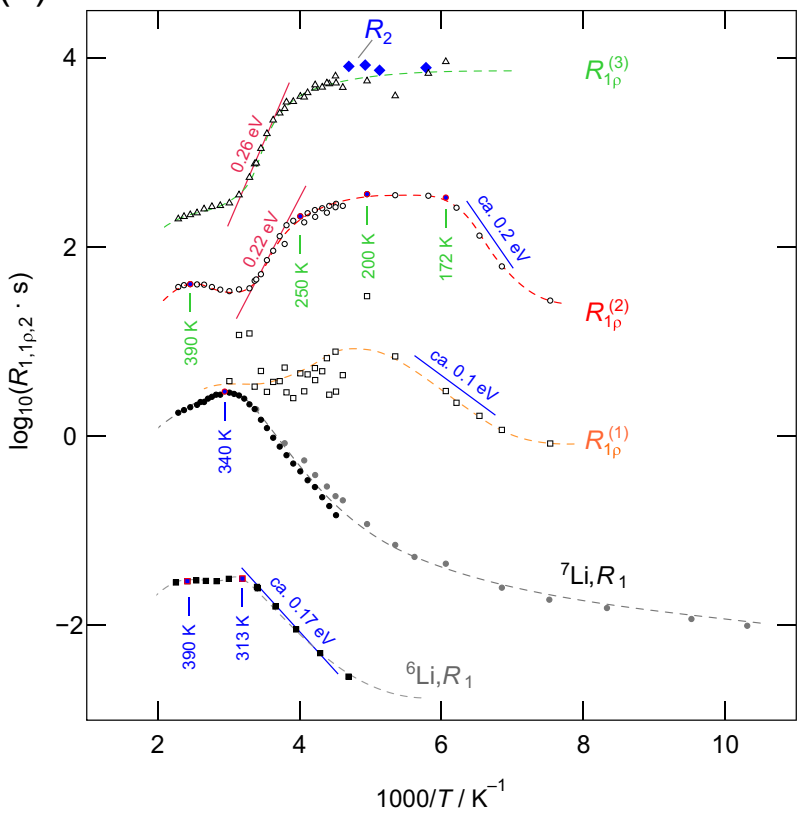

(b)



Fig. 10 (a) ${ }^{6} \mathrm{Li}$ and ${ }^{7} \mathrm{Li} \mathrm{NMR}$ (variable-temperature) spin-lattice relaxation rates of the glass-ceramic $\mathrm{Li}_{7} \mathrm{P}_{3} \mathrm{~S}_{11}$. Extremely complex spin-lattice relaxation behavior is seen manifesting in multiple relaxation processes that take place simultaneously in the sulfide. The magnetization transients to extract $R_{1 \rho}$ cannot be parameterized with a single (stretched) exponential function of the Kohlrausch-Williams-
Watts (KWW) type. Instead, a sum of three KWW functions have to be used to describe the decay of transversal magnetization adequately, see (b). One of the components seen in $M_{\rho}\left(t_{\text {lock }}\right)$ was rather similar to the rate characterizing spin-spin relaxation. For comparison, spin-spin-relaxation rates $\left(R_{2}\right)$ are shown in the Arrhenius plot, too
Looking at activation energies from conductivity and impedance spectroscopy, the values deceived from NMR are indeed in agreement with barriers as low as $0.1 \mathrm{eV}$ and $0.2 \mathrm{eV}$ reported for the glass ceramic $\mathrm{Li}_{7} \mathrm{P}_{3} \mathrm{~S}_{11}$, see the overview in ref. [64] and ref. [52]. Interestingly, purely amorphous $\mathrm{Li}_{7} \mathrm{P}_{3} \mathrm{~S}_{11}$ needs, however, to be characterized by larger activation energies in the order of $0.35 \mathrm{eV}$ or higher [136]. For Li ion conductors, usually the glassy (or Xray amorphous) forms represent better ion conductors than their crystalline counterparts, see, e.g., refs. [137-143] and ref. [144] for a recent investigation on the thiophosphate $\mathrm{Li}_{4} \mathrm{P}_{2} \mathrm{~S}_{6} . \mathrm{Li}_{7} \mathrm{P}_{3} \mathrm{~S}_{11}$ constitutes an exception. Large amorphous fractions need to be avoided since they seem to hinder the ions to mover easily over long distances. Just recently, a systematic in situ study has been published to find out the optimum synthesis parameters to prepare crystalline $\mathrm{Li}_{7} \mathrm{P}_{3} \mathrm{~S}_{11}$ as a glass ceramic [145].

\section{Conclusions and outlook}

All solid-state batteries are expected to become one of the principal actors in battery research for, e.g., electric (hybrid) vehicles. The route to realize such batteries is, however, two-fold. (i) Suitable materials have to be developed and characterized with the help of (physical) solid state chemistry and electrochemistry, then, materials engineering is needed to optimize properties and to find the right synthesis strategies to prepare processable or machineable materials. (ii) In parallel, manufacturing processes have to be developed to enable a cost-effective large scale production of batteries. The second task is as complex as the first that has to deal with conductivities and defect chemistries, the interplay of interfaces as well as chemical and electrochemical stabilities.

Over the last couple of years enormous progress has been presented especially if we regard solid electrolytes that exhibit ionic conductivities able to compete with those known for liquids. Currently, we are witnessing an encouraging starting point to develop such systems. If solid batteries with ceramic electrolytes should become the nextgeneration technology, of course, we have to find and develop even better inorganic conductors also with regard to their energy footprint and environmental friendliness. Some of these highly promising examples have been presented above. They take advantage of fast $\mathrm{Li}$ ion dynamics necessary to guarantee a low overall resistance of the battery, at least from the point of view of bulk properties. While conductivity spectroscopy, mostly applied to characterize the electrolytes, is able to monitor (average) activation energies 
from a rather macroscopic view, NMR may assist in specifying the underling rules that determine fast ion movements. Thanks to its atomic-scale point of view local barriers can be characterized and assigned to the elementary steps of $\mathrm{Li}^{+}$hopping. The results obtained need to be compared with those from computational chemistry to allow for a meaningful interpretation. Of course, in many cases NMR is also able to provide valuable structural information, e.g., as a function of state of charge or ageing processes, to complement our understanding of solid electrolytes.

Acknowledgments Open access funding provided by Graz University of Technology. We thank the Deutsche Forschungsgemeinschaft for any support (FOR 1277, Mobility of Lithium Ions in Solids). Moreover, financial support by the Austrian Federal Ministry of Science, Research and Economy, and the Austrian National Foundation for Research, Technology and Development (CD-Laboratory of Lithium Batteries: Ageing Effects, Technology and New Materials) is greatly appreciated.

Open Access This article is distributed under the terms of the Creative Commons Attribution 4.0 International License (http:// creativecommons.org/licenses/by/4.0/), which permits unrestricted use, distribution, and reproduction in any medium, provided you give appropriate credit to the original author(s) and the source, provide a link to the Creative Commons license, and indicate if changes were made.

\section{References}

1. J.M. Tarascon, Chem. Sus. Chem. 1, 777 (2008)

2. R. van Noorden, Nature 507, 26 (2014)

3. M.S. Whittingham, Chem. Rev. 104, 4271 (2004)

4. M. Armand, J.M. Tarascon, Nature 451, 652 (2008)

5. P.G. Bruce, B. Scrosati, J.M. Tarascon, Angew. Chem. Int. Ed. 47, 2930 (2008)

6. B.L. Ellis, K.T. Lee, L.F. Nazar, Chem. Mater. 22(3), 691 (2010)

7. J.B. Goodenough, Y. Kim, Chem. Mater. 22(3), 587 (2010)

8. B. Dunn, H. Kamath, J.M. Tarascon, Science 334, 928 (2011)

9. Z. Yang, J. Zhang, M.C.W. Kintner-Meyer, X. Lu, D. Choi, J.P. Lemmon, J. Liu, Chem. Rev. 111(5), 3577 (2011)

10. F. Cheng, J. Liang, Z. Tao, J. Chen, Adv. Mater 23(15), 1695 (2011)

11. H. Li, Z. Wang, L. Chen, X. Huang, Adv. Mater. 21(45), 4593 (2009)

12. M.R. Palacin, Chem. Soc. Rev. 38, 2565 (2009)

13. M. Wakihara, Mater. Sci. Engin. Rep. 33, 109 (2001)

14. C.M. Park, J.H. Kim, H. Kim, H.J. Sohn, Chem. Soc. Rev. 39, $3115(2010)$

15. M. Winter, J.O. Besenhard, Electrochem. Acta. 45, 31 (1999)

16. N. Nitta, F. Wu, J.T. Lee, G. Yushin, Mater. Today 18(5), 252 (2015)

17. M. Winter, J. Besenhard, M. Spahr, P. Novak, Adv. Mater. 10(10), 725 (1998)

18. V. Epp, M. Wilkening, Handbook of Solid State Batteries (World Scientific, Singapore, 2015), chap. Li ion dynamics in solids as seen via relaxation NMR

19. V. Tangadurai, S. Narayanan, D. Pinzaru, Chem. Soc. Rev. 43, $4714(2014)$

20. J.C. Bachman, S. Muy, A. Grimaud, H.H. Chang, N. Pour, S.F. Lux, O. Paschos, F. Maglia, S. Lupart, P. Lamp, L. Giordano, Y. Shao-Horn, Chem. Rev. 116(1), 140 (2016)

21. F. Mizuno, C. Yada, H. Iba. in Lithium-Ion Batteries, ed. by G. Pistoia (Elsevier, Amsterdam, 2014), pp. 273-291
22. V. Thangadurai, D. Pinzaru, S. Narayanan, A.K. Baral, J. Phys, Chem. Lett. 6(2), 292 (2015)

23. M. Tatsumisago, M. Nagao, A. Hayashi, J. Asian Ceram. Soc. 1(1), 17 (2013)

24. K. Takada, Acta Mater. 61(3), 759 (2013)

25. J. Bates, N. Dudney, B. Neudecker, A. Ueda, C. Evans, Solid State Ion 135, 33 (2000)

26. L. Jin, X. Junyi, L. Yue, L. Jie, L. Yanqing, Y. Changfu, Z. Jin, Z. Kai, Acta Chim. Sinica. 71(6), 869 (2013)

27. S. Jie, W. Qihui, D. Quanfeng, Z. Mingsen, W. Suntao, S. Shigang, Progr. Chem. 19(1), 66 (2007)

28. J.G. Kim, B. Son, S. Mukherjee, N. Schuppert, A. Bates, O. Kwon, M.J. Choi, H.Y. Chung, S. Park, J. Power Sources 282, $299(2015)$

29. P.H.L. Notten, F. Roozeboom, R.A.H. Niessen, L. Baggetto, Adv. Mater. 19(24), 4564 (2007)

30. L. Baggetto, R.A.H. Niessen, F. Roozeboom, P.H.L. Notten, Adv. Funct. Mater. 18(7), 1057 (2008)

31. E. Quartarone, P. Mustarelli, Chem. Soc. Rev. 40(5), 2525 (2011)

32. M.A.K.L. Dissanayake, M.A. Careem, P.W.S.K. Bandaranayake, C.N. Wijayasekera, Solid State Ion. 48, 277 (1991)

33. H.Y.P. Hong, Mater. Res. Bull. 13, 117 (1978)

34. J.L. Briant, J. Electrochem. Soc. 128, 1830 (1981)

35. N. Kamaya, K. Homma, Y. Yamakawa, M. Hirayama, R. Kanno, M. Yonemura, T. Kamiyama, Y. Kato, S. Hama, K. Kawamoto, A. Mitsui, Nature Mater. 10, 682 (2011)

36. U. von Alpen, M.F. Bell, T. Gladden, Electrochim. Acta 24, 741 (1979)

37. T. Lapp, S. Skaarup, A. Hooper, Solid State Ion 11, 97 (1983)

38. A. Kuhn, S. Narayanan, L. Spencer, G. Goward, V. Thangadurai, M. Wilkening, Phys. Rev. B 83, 094302 (2011)

39. H. Buschmann, J. Dölle, S. Berendts, A. Kuhn, P. Bottke, M. Wilkening, P. Heitjans, A. Senyshyn, H. Ehrenberg, A. Lotnyk, V. Duppel, L. Kienle, J. Janek, Phys. Chem. Chem. Phys. 13, 19378 (2011)

40. D. Rettenwander, G. Redhammer, F. Preishuber-Pflügl, L. Cheng, L. Miara, R. Wagner, A. Welzl, E. Suard, M.M. Doeff, M. Wilkening, J. Fleig, G. Amthauer, Chem. Mater. 28(7), 2384 (2016)

41. K.H. Joo, P. Vinatier, B. Pecquenard, A. Levasseur, H.J. Sohn, Solid State Ion. 160, 51 (2003)

42. X. Yu, J.B. Bates, G.E. Jellison, F.X. Hart, J. Electrochem. Soc. 144, 524 (1997)

43. F. Croce, G.B. Appetecchi, L. Persi, B. Scrosati, Nature 394, 456 (1998)

44. H. Saruwatari, T. Kuboki, T. Kishi, S. Mikoshiba, N. Takami, J. Power Sources 195, 1495 (2010)

45. P.E. Stallworth, J.J. Fontanella, M.C. Wintersgill, C.D. Scheidler, J.J. Immel, S.G. Greenbaum, A.S. Gozdz, J. Power Sources 8182, 739 (1999)

46. J.Y. Song, Y.Y. Wang, C.C. Wan, J. Electrochem. Soc. 147, 3219 (2000)

47. R. Kanno, M. Murayama, J. Electrochem. Soc. 148(7), A742 (2001)

48. S. Kondo, K. Takada, Y. Yamamura, Solid State Ion 53-56, 1183 (1992)

49. Y. Kawakami, H. Ikuta, T. Uchida, M. Wakihara, Thermochim. Acta 299, 7 (1997)

50. J.H. Kennedy, Z. Zhang, Solid State Ion 2830, 726 (1988)

51. F. Mizuno, A. Hayashi, K. Tadanaga, M. Tatsumisago, Adv. Mater. 17, 918 (2005)

52. Y. Seino, T. Ota, K. Takada, A. Hayashi, M. Tatsumisago, Energy Environ. Sci. 7, 627 (2014)

53. P. Bron, S. Johansson, K. Zick, J.S. auf der Günne, S. Dehnen, B. Roling, J. Am. Ceram. Soc. 135(42), 15694 (2013) 
54. Y.W. Hu, I.D. Raistrick, R.A. Huggins, J. Electrochem. Soc. 124, 1240 (1977)

55. N. Imanaka, T. Shimizu, G. Adachi, Solid State Ion 62, 167 (1993)

56. Y. Tomita, H. Ohki, K. Yamada, T. Okuda, Solid State Ion 136137, 351 (2000)

57. Y. Inaguma, C. Liquan, M. Itoh, T. Nakamura, T. Uchida, H. Ikuta, M. Wakihara, Solid State Commun. 86, 689 (1993)

58. P. Knauth, Solid State Ion 180, 911 (2009)

59. J.W. Fergus, J. Power Sources 195(15), 4554 (2010)

60. D.A. Weber, A. Senyshyn, K.S. Weldert, S. Wenzel, W. Zhang, R. Kaiser, S. Berendts, J. Janek, W.G. Zeier, Chem. Mater. 28(16), 5905 (2016)

61. I.H. Chu, H. Nguyen, S. Hy, Y.C. Lin, Z. Wang, Z. Xu, Z. Deng, Y.S. Meng, S.P. Ong, A.C.S. Appl, Mater. Interfac. 8(12), 7843 (2016)

62. H.J. Deiseroth, S.T. Kong, H. Eckert, J. Vannahme, C. Reiner, T. Zaiss, M. Schlosser, Angew. Chem. Int. Ed. 47, 755 (2008)

63. R. Murugan, V. Thangadurai, W. Weppner, Angew. Chem. Int. Ed. 46, 7778 (2007)

64. D. Wohlmuth, V. Epp, M. Wilkening, ChemPhysChem. 16(12), $2582(2015)$

65. S. Breuer, D. Prutsch, Q. Ma, V. Epp, F. Preishuber-Pflügl, F. Tietz, M. Wilkening, J. Mater. Chem. A 3, 21343 (2015)

66. M. Wilkening, P. Heitjans, ChemPhysChem. 13, 53 (2012)

67. R. Böhmer, K. Jeffrey, M. Vogel, Prog. Nucl. Magn. Reson. Spectrosc. 50, 87 (2007)

68. B. Ruprecht, M. Wilkening, R. Uecker, P. Heitjans, Phys. Chem. Chem. Phys 14, 11974 (2012)

69. M. Wilkening, P. Heitjans, J. Phys, Condens. Matter. 18, 9849 (2006)

70. M. Wilkening, P. Heitjans, Phys. Rev. B 77, 024311 (2008)

71. M. Wilkening, J. Heine, C. Lyness, A.R. Armstrong, P.G. Bruce, Phys. Rev. B 80, 064302 (2009)

72. M. Wilkening, A. Kuhn, P. Heitjans, Phys. Rev. B 78, 054303 (2008)

73. M. Wilkening, C. Lyness, A.R. Armstrong, P.G. Bruce, J. Phys. Chem. C 113, 4741 (2009)

74. A. Kuhn, P. Sreeraj, R. Pöttgen, H.D. Wiemhöfer, M. Wilkening, P. Heitjans, J. Am. Chem. Soc. 133, 11018 (2011)

75. P. Heitjans, S. Indris, J. Phys. Condens. Matter. 15(30), R1257 (2003)

76. J. Jamnik, J. Maier, Phys. Chem. Chem. Phys. 5, 5215 (2003)

77. J. Maier, Phys. Chem. Chem. Phys 11, 3011 (2009)

78. C.-L. Tsai, V. Roddatis, C.V. Chandran, Q. Ma, S. Uhlenbruck, Bram M., Heitjans P., O. Guillon, ACS Appl. Mater. Interfaces 8(16), 10617 (2016)

79. Y. Iriyama, Z. Ogumi, Handbook of Solid State Batteries (World Scientific, Singapore, 2015), chap. Solid ElectrodeInorganic Solid Electrolyte Interface for Advanced All-SolidState Rechargeable Lithium Batteries

80. M.R. Busche, T. Drossel, T. Leichtweiss, D.A. Weber, M. Falk, M. Schneider, M.-L. Reich, H. Sommer, P. Adelhelm, J. Janek, Nature Chem. 8(5), 426 (2016)

81. S. Wenzel, S. Randau, T. Leichtweiß, D.A. Weber, J. Sann, W.G. Zeier, J. Janek, Chem. Mater. 28(7), 2400 (2016)

82. Y. Zhu, X. He, Y. Mo, J. Mater. Chem. A 4, 3253 (2016)

83. W.D. Richards, L.J. Miara, Y. Wang, J.C. Kim, G. Ceder, Chem. Mater. 28(1), 266 (2016)

84. Y. Zhu, X. He, Y. Mo, ACS Appl. Mater. Interfaces 7(42), 23685 (2015)

85. X. Han, Y. Gong, K. Fu, X. He, G.T. Hitz, J. Dai, A. Pearse, B. Liu, H. Wang, G. Rubloff, Y. Mo, V. Thangadurai, E.D. Wachsman, L. Hu, Nature Mater. pp. in press, doi:10.1038/ nmat4821 (2016)
86. K. Takada, Handbook of Solid State Batteries (World Scientific, Singapore, 2015), chap. Interface of 4 V Cathodes with Sulfide Electrolytes

87. M. Gellert, K.I. Gries, J. Sann, E. Pfeifer, K. Volz, B. Roling, Solid State Ion 287, 8 (2016)

88. W.E. Tenhaeff, E. Rangasamy, Y. Wang, A.P. Sokolov, J. Wolfenstine, J. Sakamoto, N.J. Dudney, ChemElectroChem. 1, 375 (2014)

89. K. Funke, Prog. Solid State Chem. 22, 111 (1993)

90. K.L. Ngai, Comments Solid State Phys. 9, 141 (1980)

91. K.L. Ngai, J. de Physique IV 2, C2 61 (1992)

92. M. Wilkening, V. Epp, A. Feldhoff, P. Heitjans, J. Phys. Chem. C 112(25), 9291 (2008)

93. K.L. Ngai, Phys. Rev. B 48, 13481 (1993)

94. C. León, M.L. Lucía, J. Santamaría, M.A. París, J. Sanz, A. Várez, Phys. Rev. B 54, 184 (1996)

95. I. Svare, F. Borsa, D.R. Torgeson, S.W. Martin, Phys. Rev. B 48, 9336 (1993)

96. M. Wilkening, W. Küchler, P. Heitjans, Phys. Rev. Lett. 97, 065901 (2006)

97. P. Heitjans, A. Schirmer, S. Indris, in Diffusion in Condensed Matter-Methods, Materials, Models. 2nd edn, ed. by P. Heitjans, J. Krger (Springer, Berlin, 2005), pp. 369-415

98. E. Fukushima, S. Roeder, Experimental Pulse NMR (AddisonWesley, Reading, 1981)

99. N. Bloembergen, E.M. Purcell, R.V. Pound, Phys. Rev. 73, 679 (1948)

100. A. Bunde, W. Dieterich, P. Maass, M. Meyer, in Diffusion in Condensed Matter-Methods, Materials, Models. 2nd edn, ed. by P. Heitjans, J. Krger (Springer, Berlin, 2005), pp. 813-856

101. E. Goebel, W. Müller-Warmuth, H. Olyschläger, H. Dutz, J. Magn. Res. 36, 371 (1979)

102. D.C. Ailion, C.P. Slichter, Phys. Rev. 137, A235 (1965)

103. D.C. Look, I.J. Lowe, J. Chem. Phys. 44, 2995 (1966)

104. C.P. Slichter, D. Ailion, Phys. Rev. 135, A1099 (1964)

105. D. Wolf, Phys. Rev. B 10, 2724 (1974)

106. T.J. Rowland, F.Y. Fradin, Phys. Rev. 182, 760 (1969)

107. A. Kuhn, M. Kunze, P. Sreeraj, H.D. Wiemhöfer, V. Thangadurai, M. Wilkening, P. Heitjans, Solid State Nucl. Magn. Res. 42, 2 (2012)

108. A. Soloninin, A. Skripov, A. Buzlukov, A. Stepanov, J. Solid State Chem. 182(9), 2357 (2009)

109. R.L. Corey, D.T. Shane, R.C. Bowman, M.S. Conradi, J. Phys. Chem. C 112, 19784 (2008)

110. K. Takahashi, K. Hattori, T. Yamazaki, M.M.K. Takada, S. Orimo, H. Maekawa, H. Takamura, J. Power Sources 226, 61 (2013)

111. D. Sveinbjörnsson, A.S. Christiansen, R. Viskinde, P. Norby, T. Vegge, J. Electrochem. Soc. 161(9), A1432 (2014)

112. M. Matsuo, H. Takamura, H. Maekawa, H. Li, S. Orimo, Appl. Phys. Lett. 94, 084103 (2009)

113. H. Maekawa, M. Matsuo, H. Takamura, M. Ando, Y. Noda, T. Karahashi, S. Orimo, J. Am. Chem. Soc. 131, 894 (2009)

114. A.F. McDowell, C.F. Mendelsohn, M.S. Conradi, R.C. Bowman, A.J. Maeland, Phys. Rev. B 51, 6336 (1995)

115. P.M. Richards, in Topics in Current Physics, ed. by M.B. Salamon, Vol. 15 (Springer, Berlin, p. 1979)

116. V. Epp, M. Wilkening, Phys. Rev. B 82, 020301 (2010)

117. R. Wagner, G.J. Redhammer, D. Rettenwander, A. Senyshyn, W. Schmidt, M. Wilkening, G. Amthauer, Chem. Mater. 28, 1861 (2016)

118. P. Bottke, D. Rettenwander, W. Schmidt, G. Amthauer, M. Wilkening, Chem. Mater. 27, 6571 (2015)

119. J. Awaka, N. Kijima, H. Hayakawa, J. Akimoto, J. Solid State Chem. 182, 2046 (2009) 
120. J. Sakamoto, Handbook of Solid State Batteries (World Scientific, Singapore, 2015), chap. Super-ionic conducting oxide electrolytes

121. D. Rettenwander, A. Welzl, L. Cheng, J. Fleig, M. Musso, E. Suard, M.M. Doeff, G.J. Redhammer, G. Amthauer, Inorg. Chem. 54(21), 10440 (2015)

122. D. Rettenwander, C.A. Geiger, M. Tribus, P. Tropper, R. Wagner, G. Tippelt, W. Lottermoser, G. Amthauer, J. Solid State Chem. 230, 266 (2015)

123. M.D. Johannes, N.A.W. Holzwarth, Handbook of Solid State Batteries (World Scientific, Singapore, 2015), chap. Crystalline Inorganic Solid Electrolytes: Computer Simulations and Comparisons with Experiment

124. D. Rettenwander, J. Langer, W. Schmidt, C. Arrer, K.J. Harris, V. Terskikh, G.R. Goward, M. Wilkening, G. Amthauer, Chem. Mater. 27(8), 3135 (2015)

125. V. Epp, Q. Ma, E.M. Hammer, F. Tietz, M. Wilkening, Phys. Chem. Chem. Phys. 17, 32115 (2015)

126. R. Böhmer, T. Jörg, F. Qi, A. Titze, Chem. Phys. Lett. 316, 419 (2000)

127. R. Böhmer, J. Magn. Res. 147, 78 (2000)

128. B. Koch, M. Vogel, Solid State Nucl. Magn. Res. 34, 37 (2008)

129. C. Brinkmann, S. Faske, B. Koch, M. Vogel, Z. Phys. Chem. 224, $1535(2010)$

130. B. Ruprecht, H. Billetter, U. Ruschewitz, M. Wilkening, J. Phys. Cond. Matter. 22, 245901 (2010)

131. M. Storek, R. Böhmer, J. Phys. Chem. C 120(14), 7767 (2016)

132. C. Vinod Chandran, S. Pristat, E. Witt, F. Tietz, P. Heitjans, J. Phys. Chem. C 120(16), 8436 (2016)
133. V. Epp, O. Gün, H.J. Deiseroth, M. Wilkening, J. Phys. Chem. Lett. 4, 2118 (2013)

134. G. Redhammer, D. Rettenwander, S. Pristat, E. Dashjav, C. Kumar, D. Topa, F. Tietz, Solid State Sci. 60, 99 (2016)

135. B. Lang, B. Ziebarth, C. Elsässer, Chem. Mater. 27(14), 5040 (2015)

136. Y. Seino, M. Nakagawa, M. Senga, H. Higuchi, K. Takada, T. Sasaki, J. Mater. Chem. A 3, 2756 (2015)

137. D. Wohlmuth, V. Epp, B. Stanje, A.M. Welsch, H. Behrens, M. Wilkening, J. Am. Ceram. Soc. 99(5), 1687 (2016)

138. T. Matsuo, M. Shibasaki, T. Katsumata, Y. Onoda, Jap. J. Appl. Phys. 33(7R), 3913 (1994)

139. T. Matsuo, M. Shibasaki, N. Saito, T. Katsumata, J. Appl. Phys. 79(4), 1903 (1996)

140. P. Heitjans, M. Masoud, A. Feldhoff, M. Wilkening, Faraday Discuss. 134, 67 (2007)

141. D. Wohlmuth, V. Epp, P. Bottke, I. Hanzu, B. Bitschnau, I. Letofsky-Papst, M. Kriechbaum, H. Amenitsch, F. Hofer, M. Wilkening, J. Mater. Chem. A 2, 20295 (2014)

142. S.G. Bishop, P.J. Bray, J. Chem. Phys. 48(4), 1709 (1968)

143. W. Franke, P. Heitjans, Ber. Bunsenges. Phys. Chem. 96(11), 1674 (1992)

144. C. Dietrich, M. Sadowski, S. Sicolo, D.A. Weber, S.J. Sedlmaier, K.S. Weldert, S. Indris, K. Albe, J. Janek, W.G. Zeier, Chem. Mater. 28(23), 8764 (2016)

145. M.R. Busche, D.A. Weber, Y. Schneider, C. Dietrich, S. Wenzel, T. Leichtweiß, D. Schröder, W. Zhang, H. Weigand, D. Walter, S.J. Sedlmaier, D. Houtarde, L.F. Nazar, J. Janek, Chem. Mater. 28, 6152 (2016) 